\title{
Numerical Study on Turbulent Forced Convection and Heat Transfer Characteristic in a Circular Tube with V-Orifice
}

\author{
Withada Jedsadaratanachai ${ }^{1}$ and Amnart Boonloi ${ }^{2}$ \\ ${ }^{1}$ Department of Mechanical Engineering, Faculty of Engineering, King Mongkut's Institute of Technology Ladkrabang, \\ Bangkok 10520, Thailand \\ ${ }^{2}$ Department of Mechanical Engineering Technology, College of Industrial Technology, King Mongkut's University of \\ Technology North Bangkok, Bangkok 10800, Thailand
}

Correspondence should be addressed to Amnart Boonloi; amnartb@kmutnb.ac.th

Received 9 November 2016; Accepted 20 March 2017; Published 15 May 2017

Academic Editor: Dimitrios E. Manolakos

Copyright (C) 2017 Withada Jedsadaratanachai and Amnart Boonloi. This is an open access article distributed under the Creative Commons Attribution License, which permits unrestricted use, distribution, and reproduction in any medium, provided the original work is properly cited.

Performance assessments on heat transfer, pressure loss, and thermal enhancement factor in the circular tube heat exchanger inserted with the V-orifices are investigated numerically. The influences of the blockage ratio, gap spacing ratio, and orifice arrangement are reported for turbulent regime, $\mathrm{Re}=3000-10,000$. The finite volume method and SIMPLE algorithm are selected to solve the present problem. The mechanisms on flow and heat transfer characteristics are described. The periodic concepts on flow and heat transfer are also studied. The numerical results show that the gap spacing ratio is main reason for the changes of the flow and heat transfer topologies. The gap distance helps to adjust the optimum point of the thermal performance, especially at high flow blockage ratio. In addition, the optimum thermal performance of the present system is around 2.25 at the lowest Reynolds number, $\mathrm{Re}=3000$.

\section{Introduction}

The passive technique had been used to improve various types of the heat exchangers. The passive method does not require the additional power to enhance the heat transfer rate and thermal performance. The purpose for the passive technique is to disturb the thermal boundary layer on the heat transfer surface and improve the fluid mixing by the vortex generators or turbulators: winglet, wing, rib, baffle, and so forth. The selection of the vortex generator depends on the application of the heat exchanger.

The circular ring (like orifice) is widely used in the tube heating system to augment the heat transfer rate and performance. The configuration of the circular ring is presented as Figure 1. Kongkaitpaiboon et al. [1] experimentally investigated convective heat transfer and friction loss in a circular tube with circular-ring vortex generators. The influences of the diameter ratios (diameter of the orifice to the diameter of the tube) and pitch ratios $(P / D)$ were examined for turbulent regime, $\mathrm{Re}=4000-20,000$. They reported that the heat transfer augmentation is around $57-195 \%$ when compared with the smooth circular tube without vortex generator. The selection of the conical-ring to improve the heat exchanger was also reported by many researchers [1-15]. They found that the conical-ring in the heat exchanger enhances heat transfer rate and thermal efficiency but also increases very large pressure loss, especially at low diameter ratio (low flow area).

The circular-ring was applied with the twisted tape called "twisted-ring turbulators," which used to enhance thermohydraulic performance in the tube heat exchanger [16]. The parameters, width and pitch ratios, were studied at $\operatorname{Re}=6000-20,000$ by the experimental method. The twistedring was compared with the typical conical-ring on heat transfer and pressure loss. They concluded that the twistedring provides higher heat transfer rate, pressure loss, and thermal performance than the typical conical-ring. They also stated that the maximum thermal enhancement is around 1.24 at $\operatorname{Re}=6000$.

The V-shaped vortex generators [17-28] had been designed to enhance heat transfer rate in the heating and cooling sections. The $\mathrm{V}$-shaped vortex generators give high 


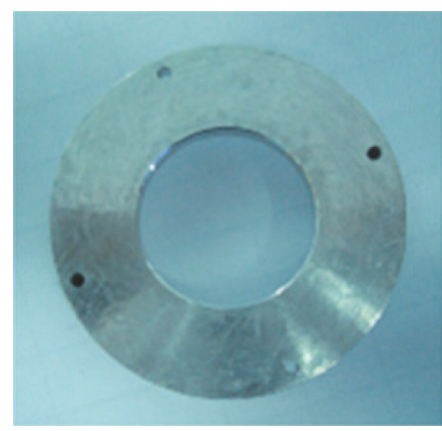

$d / D=0.5$

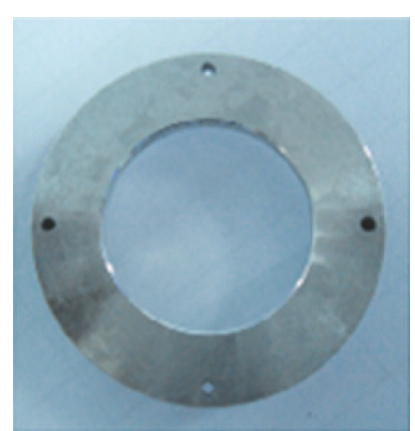

$d / D=0.6$

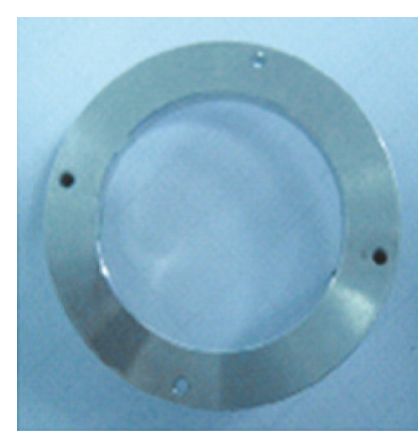

$d / D=0.7$

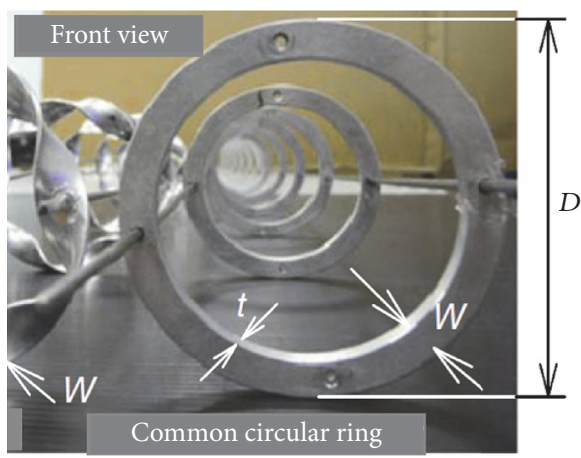

FIGURE 1: The configuration of the general circular ring/orifice [1].

effectiveness to increase heat transfer when compared with the other types of the vortex generators such as inclined shape, curve shape, wing, and winglet. The height, flow attack angle, pitch spacing, thickness, and so forth of the vortex generators are important factors, which effect for the heat transfer augmentation.

In the present work, the typical turbulator is modified by combining the configuration of circular ring with that of Vshaped baffle and presented as "V-orifice." The aim of this research is to generate strong vortex flow, which disturbs the thermal boundary layer near the tube wall. The boundary layer disturbance is a reason for the enhancements of heat transfer and thermal efficiency. The influences of the baffle height (or diameter ratio) and flow directions are investigated numerically. To reduce the pressure loss, the gap spacing between the V-orifice and tube wall is also varied. The forced convection heat transfer with turbulent regime at $\mathrm{Re}=$ $3000-10,000$ is considered for the present work.

\section{Physical Domain}

Figure 2 presents the configuration of the circular tube heat exchanger inserted with the V-orifices. The diameter of the circular tube, $D$, is equal to $0.05 \mathrm{~m}$. The distance between the $V$-orifices, $P$, is fixed at $0.05 \mathrm{~m}$ or $P / D=1(P R=1)$. The flow attack angle around $45^{\circ}$ of the $\mathrm{V}$-orifice is applied for all cases. The height of the V-orifice, $b$, and gap between $\mathrm{V}$ orifice and tube wall, $g$, are varied. The $b / D$ or BR is called the blockage ratio, while the $g / D$ is known as the gap spacing ratio. The V-tip of the V-orifice points to both downstream and upstream arrangements called "V-Downstream (VD)" and "V-Upstream (VU)," respectively. The code of the case investigations is reported as Table 1 .

The structures of the tube heat exchanger inserted with the V-orifices at various gaps are depicted as Figure 3. The geometries of the computational domain in $y-z$ plane are displayed as Figures 4 and 5.

\section{Mathematical Foundation, Assumption, and Boundary Condition}

The flow and heat transfer are steady in three dimensions. The flow is turbulent and incompressible. The radiation heat transfer, body force, natural convection, and viscous dissipation are regarded. The fluid properties are assumed as constant at average bulk mean temperature. The periodic condition is used for the inlet and outlet of the computational domain. The uniform heat flux around $600 \mathrm{~W} / \mathrm{m}^{2}$ is applied for the tube wall. The V-orifices are set with adiabatic wall condition (insulator). No-slip wall condition is used for all surfaces of the domain.

The circular tube flow is solved by the continuity equation, Navier-Stokes equation, and energy equation. The mathematical foundation and numerical method are referred to by [29]. The realizable $k-\varepsilon$ model [30] is selected for the current numerical solution.

$$
\begin{aligned}
\frac{\partial}{\partial t} & (\rho k)+\frac{\partial}{\partial x_{j}}\left(\rho k u_{j}\right) \\
& =\frac{\partial}{\partial x_{j}}\left[\left(\mu+\frac{\mu_{t}}{\sigma_{k}}\right) \frac{\partial k}{\partial x_{j}}\right]+G_{k}+G_{b}-\rho \varepsilon+Y_{M}+S_{k},
\end{aligned}
$$


TABLE 1: Code of the case studies.

\begin{tabular}{lccccc}
\hline$g / D$ & \multicolumn{3}{c}{ V-tip pointing downstream } & & \multicolumn{2}{c}{ V-tip pointing upstream } \\
& $\mathrm{BR}=0.1$ & $\mathrm{BR}=0.2$ & $\mathrm{BR}=0.3$ & $\mathrm{BR}=0.1$ & $\mathrm{BR}=0.2$ \\
\hline 0 & $A-1 D$ & $B-1 D$ & $C-1 D$ & $A-1 U$ & $B-1 U$ \\
0.05 & $A-2 D$ & $B-2 D$ & $C-2 D$ & $A-2 U$ & $B-2 U$ \\
0.10 & $A-3 D$ & $B-3 D$ & $C-3 D$ & $A-3 U$ & $B-3 U$ \\
0.15 & $A-4 D$ & $B-4 D$ & $C-4 D$ & $A-4 U$ & $B-4 U$ \\
0.20 & $A-5 D$ & $B-5 D$ & $C-5 D$ & $A-5 U$ & $B-5 U$ \\
0.25 & $A-6 D$ & $B-6 D$ & $C-6 D$ & $A-6 U$ & $B-6 U$ \\
0.30 & $A-7 D$ & $B-7 D$ & & $A-7 U$ & $B-3 U$ \\
0.35 & $A-8 D$ & & & $A-8 U$ & $C-4 U$ \\
\hline
\end{tabular}
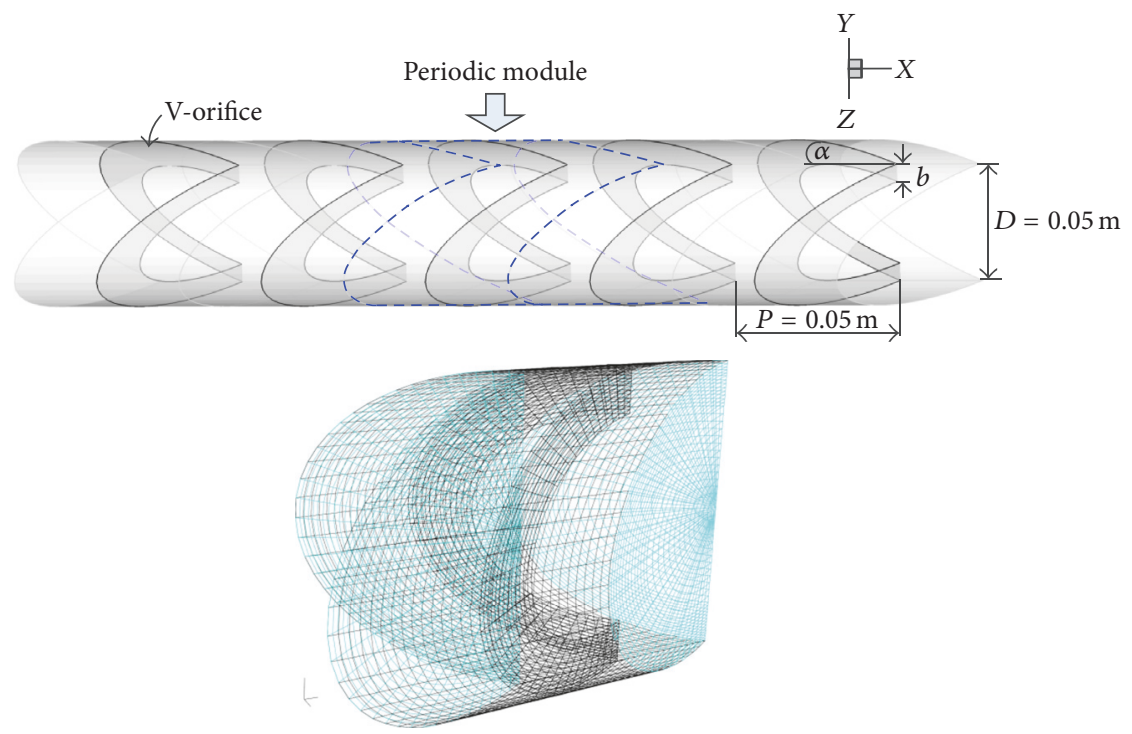

FIgURE 2: The tube heat exchanger inserted with V-orifice.

$$
\begin{aligned}
\frac{\partial}{\partial t}(\rho \varepsilon) & +\frac{\partial}{\partial x_{j}}\left(\rho \varepsilon u_{j}\right) \\
= & \frac{\partial}{\partial x_{j}}\left[\left(\mu+\frac{\mu_{t}}{\sigma_{\varepsilon}}\right) \frac{\partial \varepsilon}{\partial x_{j}}\right]+\rho C_{1} S \varepsilon+\rho C_{2} \frac{\varepsilon^{2}}{k+\sqrt{v \varepsilon}} \\
& +C_{1 \varepsilon} \frac{\varepsilon}{k} C_{3 \varepsilon} G_{b}+S_{\varepsilon},
\end{aligned}
$$

where

$$
C_{1}=\max \left[0.43, \frac{\eta}{\eta+5}\right], \quad \eta=S \frac{k}{\varepsilon}, S=\sqrt{2 S_{i j} S_{i j}} .
$$

The constant values are as follows:

$$
\begin{aligned}
C_{1 \varepsilon} & =1.44, \\
C_{2} & =1.9, \\
\sigma_{k} & =1.0, \\
\sigma_{\varepsilon} & =1.2 .
\end{aligned}
$$

The QUICK numerical scheme is discretized for all governing equations, decoupling with the SIMPLE algorithm and solved using a finite volume approach [31]. The solutions are set to be converged when the normalized residuals are less than $10^{-9}$ and $10^{-5}$ for the energy equation and the other variables.

The important parameters are Reynolds number, friction factor, local Nusselt number, average Nusselt number, and thermal enhancement factor printed as (4)-(8), respectively. 


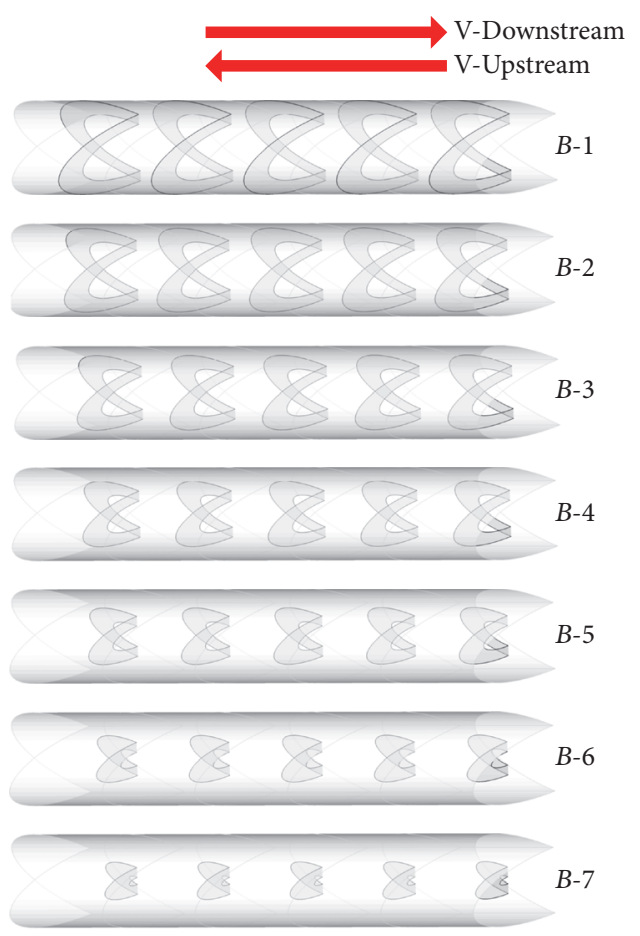

FIgURE 3: The tube heat exchanger inserted with V-orifice at various gap ratios.

$$
\mathrm{TEF}=\left.\frac{h}{h_{0}}\right|_{p p}=\left.\frac{\mathrm{Nu}}{\mathrm{Nu}_{0}}\right|_{p p}=\frac{\left(\mathrm{Nu} / \mathrm{Nu}_{0}\right)}{\left(f / f_{0}\right)^{1 / 3}} .
$$

The Nusselt number and friction factor of the smooth tube are presented as $\mathrm{Nu}_{0}$ and $f_{0}$, respectively.

\section{Numerical Result and Discussion}

The comparisons between the numerical results with the experimental results and the values from the correlations are reported in the first part, while the periodic concepts on flow and heat transfer are illustrated in the next part. The mechanisms on flow and heat transfer in the tube heat exchanger are depicted in the third part, while the performance assessments on heat transfer, pressure loss, and thermal enhancement factor are described in the last part.

4.1. Numerical Validation. The validation of the computational domain is the most important procedure for the numerical investigation. The computational validations of the smooth circular tube are performed by comparison between the present results with the values from the correlations [32] on the Nusselt number and friction loss. The results are reported as Table 2 .

As the results, the maximum deviations of the Nusselt number and friction factor are around 5.48 and $8.28 \%$, respectively.

The computational model is also validated with the experimental results. The case of $b / D=0.25$ and $P / D=6$ with $\operatorname{Re}=4000-10,000$ is selected to verify the accuracy

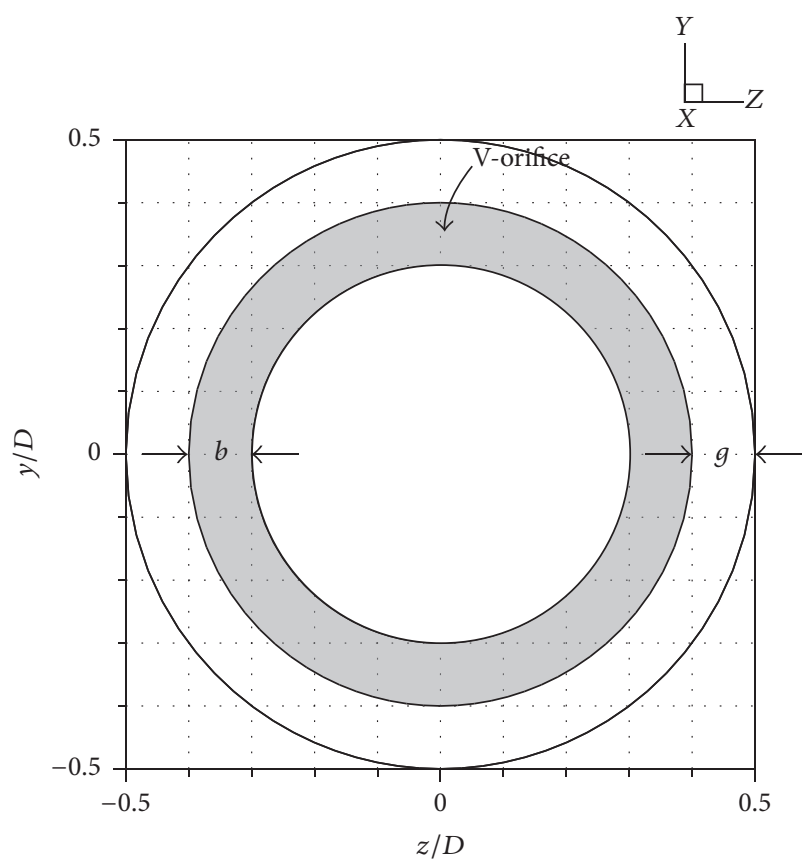

FIgURE 4: The tube configuration in $y$ - $z$ plane.

of the domain. The realizable $k-\varepsilon$ model is used to examine the present problem. The numerical results reveal that the deviations of the Nusselt number and friction factor are around $6 \%$ and $15 \%$, respectively. The evaluation between the numerical and experimental results is reported as Figure 6.

The hexahedral mesh is selected for all numerical domains. The grid independence test is done by compared four sets of grid cell. The 120000, 180000, 240000, and 360000 mesh are generated for the case of $A-1 D$. The augmentation of grid cell from 180000 to 240000 has no effect for the heat transfer rate and pressure loss. Therefore, the computational domain is produced with grid cell around 180000 in all cases.

As the preliminary results, it can be concluded that computational domain has reliability to predict flow and heat transfer behaviors in the tube heat exchanger installed with the V-orifices.

4.2. Periodic Flow and Heat Transfer Profile. The periodic concepts on flow and heat transfer of the computational domain are tested. Figure 7 shows full domain of the tube heat exchanger inserted with $\mathrm{V}$-orifices. The boundary conditions for the full domain are also presented in the figure. The flow and heat transfer profiles are described as Figures 8 and 9, respectively. The flow configuration is separated into two zones: periodic flow and fully developed periodic flow. The periodic flow means that the pattern of flow for each module is similar, but the value of $u / u_{0}$ is not equal. The fully developed periodic flow means that the value and profile of the flow are identical. The periodic flow profile is found around $x / D=3$ (the 3rd module), while the fully developed periodic flow profile is detected around $x / D=6$ (the 6 th module). The periodic concept of heat transfer profile is found to be similar to the flow profile. In conclusion, the periodic condition can apply for the computational 
TABLE 2: The validations of the Nusselt number and friction factor for the smooth tube.

\begin{tabular}{|c|c|c|c|c|c|c|}
\hline \multirow{2}{*}{$\operatorname{Re}$} & \multicolumn{2}{|c|}{ Exact solution } & \multicolumn{2}{|c|}{ Present prediction } & \multicolumn{2}{|c|}{ Error (\%) } \\
\hline & $\mathrm{Nu}$ & $f$ & $\mathrm{Nu}$ & $f$ & $\mathrm{Nu}$ & $f$ \\
\hline 3000 & 10.03803 & 0.04556 & 10.56550 & 0.04877 & 5.25470 & 7.04776 \\
\hline 4000 & 13.54157 & 0.04144 & 13.84410 & 0.04323 & 2.23410 & 4.30488 \\
\hline 6000 & 19.61155 & 0.03652 & 20.68550 & 0.03955 & 5.47613 & 8.27531 \\
\hline 8000 & 24.99410 & 0.03355 & 24.89550 & 0.03452 & -0.39450 & 2.89340 \\
\hline 10000 & 29.96493 & 0.03148 & 31.22000 & 0.03222 & 4.18847 & 2.33704 \\
\hline
\end{tabular}

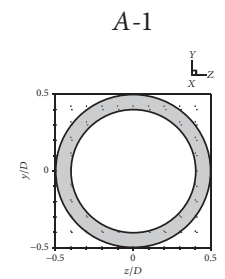

$B-1$

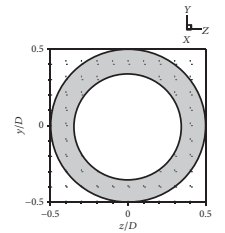

C-1

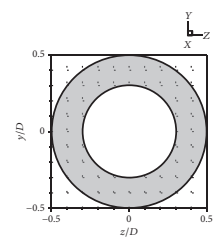

A-2

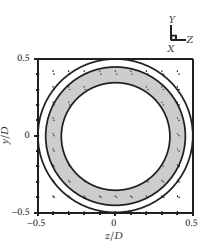

$B-2$

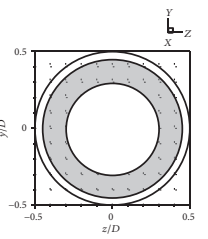

C-2
$A-3$

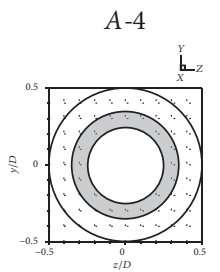

$B-4$

B-3

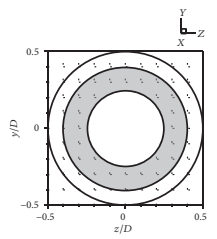

C-3

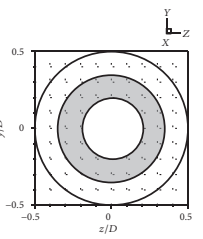

C-4
A-5

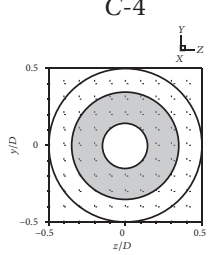

B-5

C-5
A-6
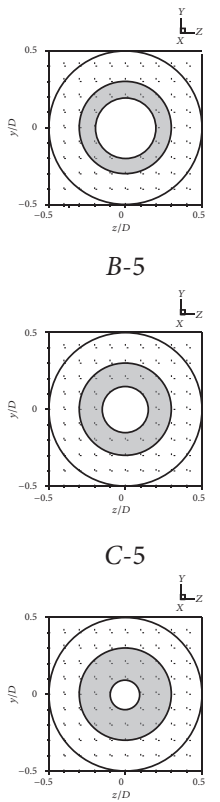

B-6

C-6
A-7

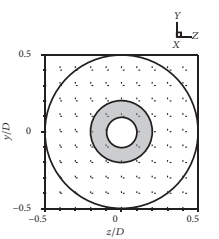

B-7

A-8
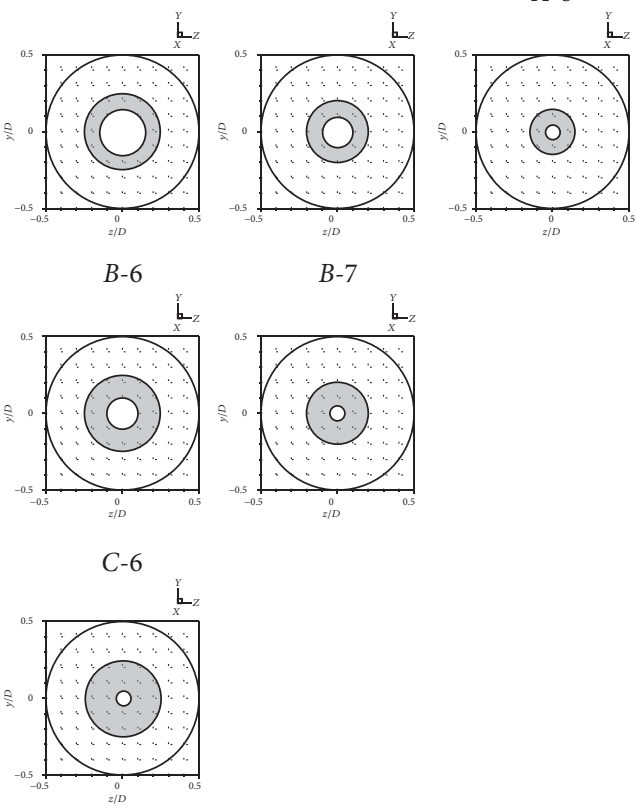

FIGURE 5: The tube configuration in $y$ - $z$ plane at various cases.

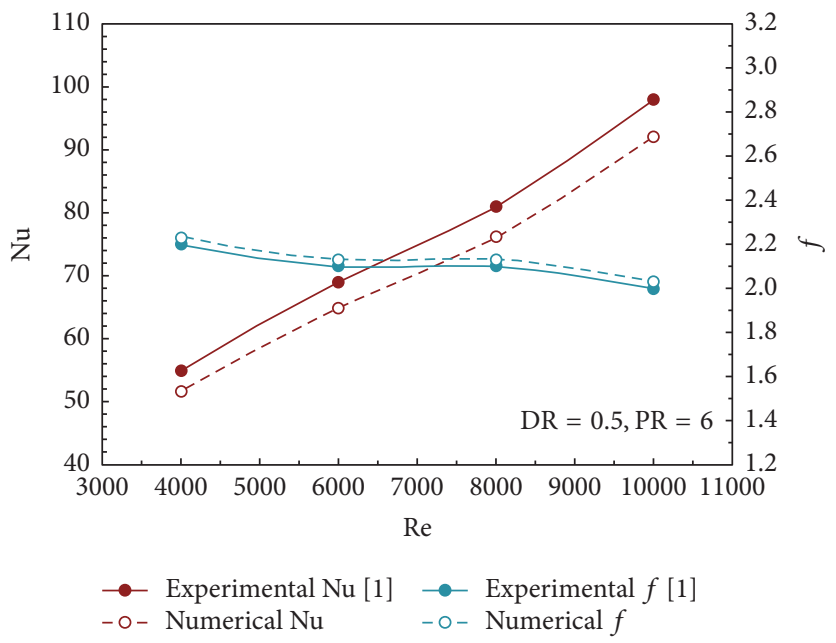

FIgURE 6: The validations on Nusselt number and friction factor between numerical and experimental results. 


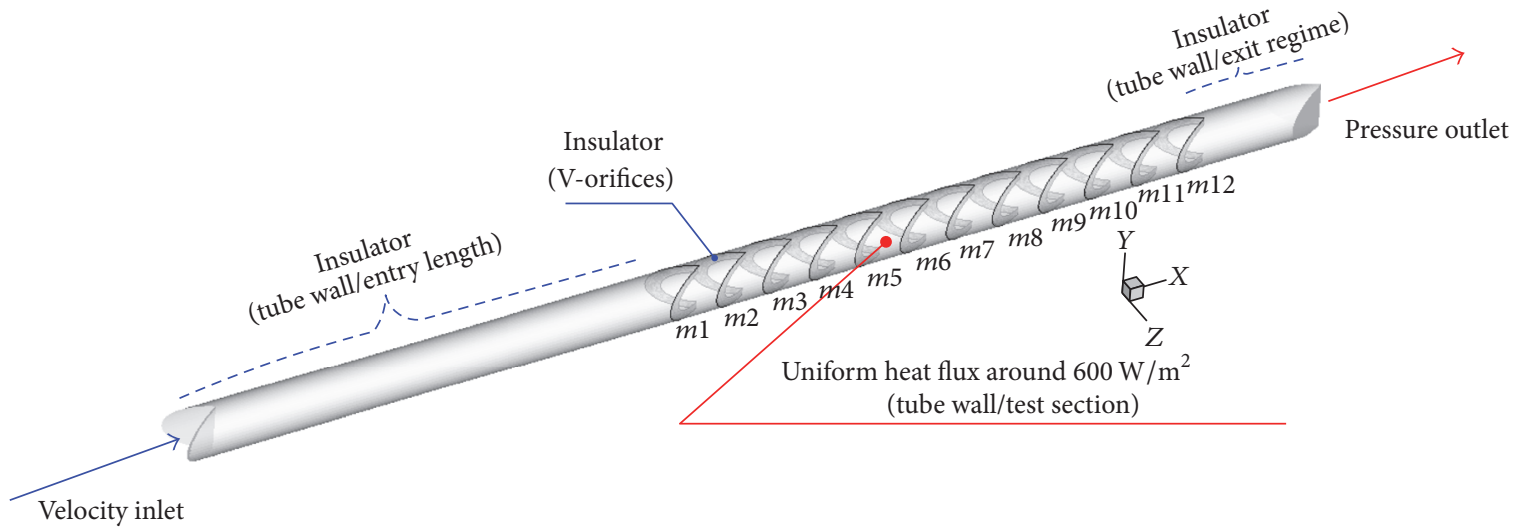

FIGURE 7: Full length of the tube inserted with V-orifices and boundary condition.
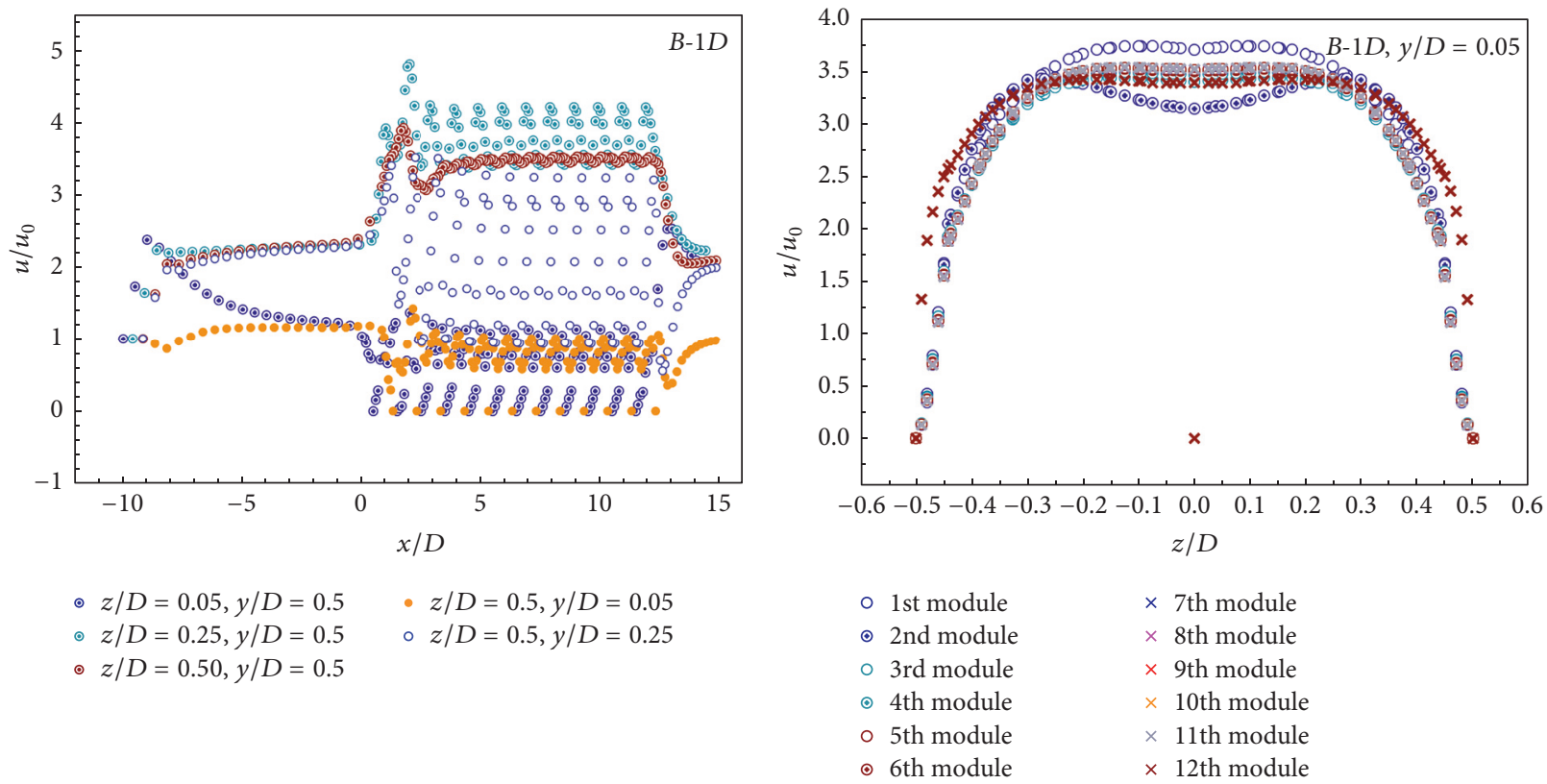

(a)

(b)

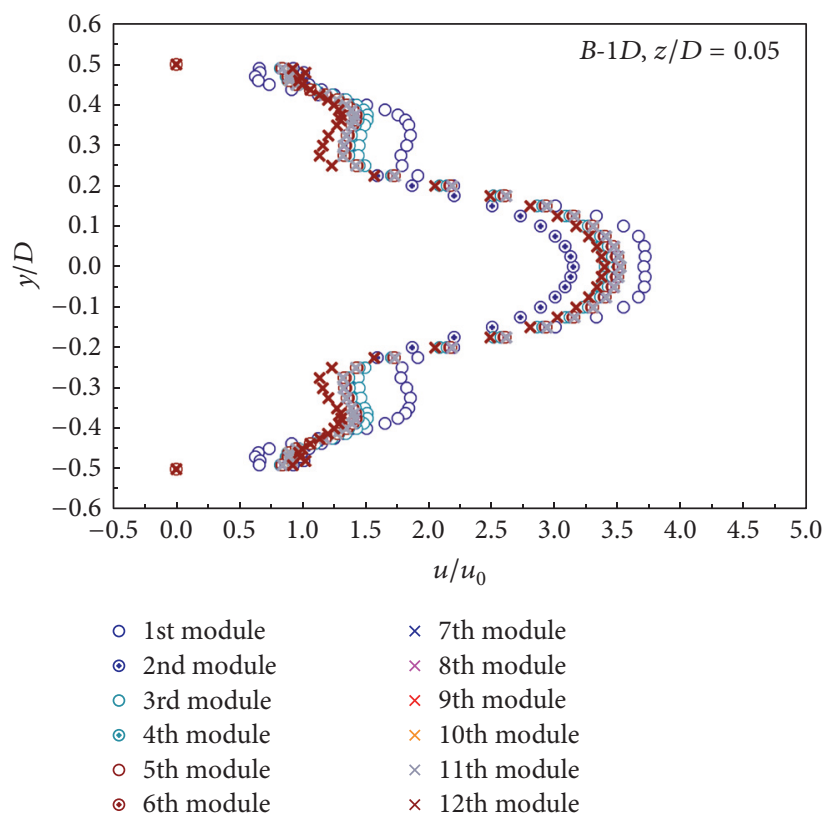

(c)

Figure 8: Periodic flow test: (a) $u / u_{0}$ versus $x / D$, (b) $u / u_{0}$ versus $z / D$, and (c) $y / D$ versus $u / u_{0}$. 


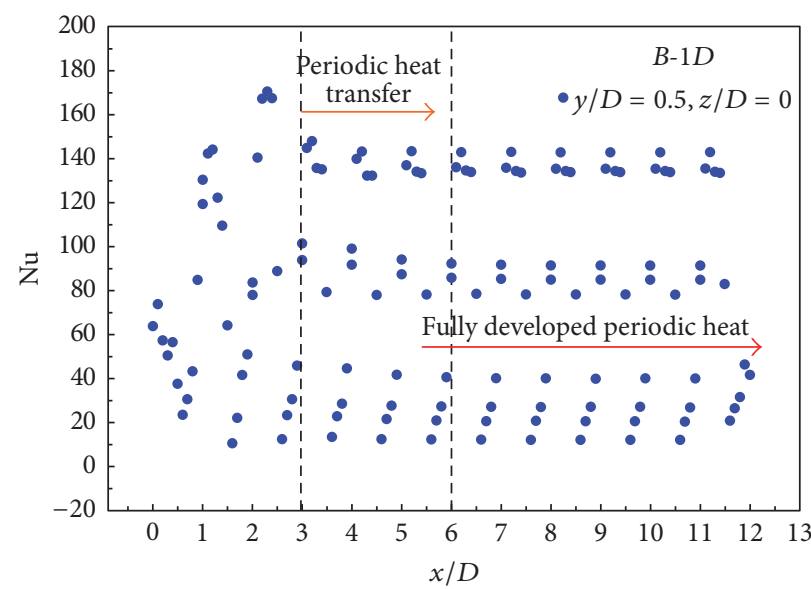

Figure 9: Periodic heat transfer test; Nu versus $x / D$, at $y / D=0.5$ and $z / D=0$.

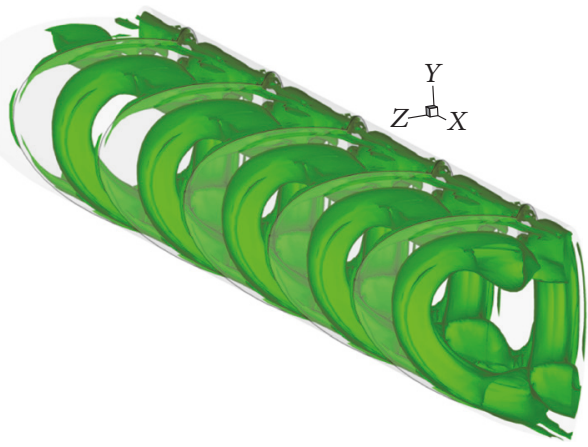

(a)

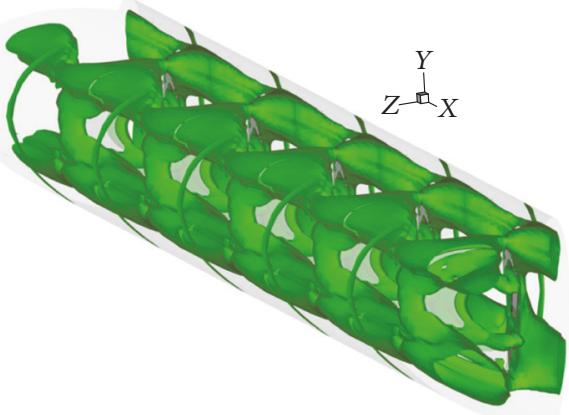

(c)

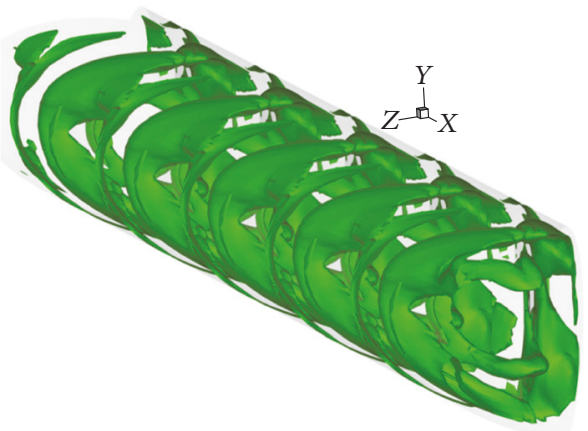

(b)

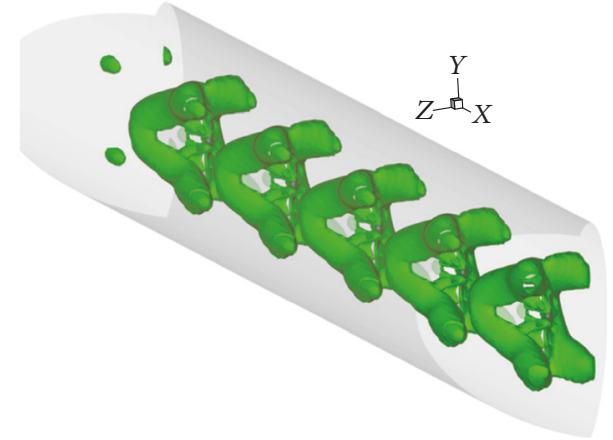

(d)

Figure 10: Iso-surface at $\lambda_{2}=-2500$ for (a) $B-1 D$, (b) $B-3 D$, (c) $B-5 D$, and (d) $B-7 D$ for $\operatorname{Re}=3000$.

domain to save investigated time and numbers of grid cell.

4.3. Flow and Heat Transfer Behaviors. The flow configurations in the test tube inserted with the V-orifices are illustrated by iso-surface and streamlines in $y$ - $z$ plane. Figures 10(a), 10(b), 10(c), and 10(d) show the iso-surface with $\lambda_{2}=$ -2500 for $B-1 D, B-3 D, B-5 D$, and $B-7 D$, respectively, at $\mathrm{Re}=$ 3000. The iso-surface is an indicator of the vortex core, produced by the $\mathrm{V}$-orifices. As the figures, the vortex flows are found behind the $\mathrm{V}$-orifice in all cases. The reduction of the vortex core is found when the gap between the $\mathrm{V}$-orifice and tube wall decreased. $B-1 D$ performs the largest vortex core, while $B-7 D$ provides the opposite trend. The similar results are found in cases $B-1 U, B-3 U, B-5 U$, and $B-7 U$ as depicted in Figures 11(a), 11(b), 11(c), and 11(d), respectively.

The streamlines in $y-z$ planes at various $x / D$ values for $B-1 D, B-3 D, B-5 D$, and $B-7 D$ with $\mathrm{Re}=3000$ are shown in Figure 12. For all cases, the vortex flows are detected through the test section. Except for $B-3 D$, the four main vortex 


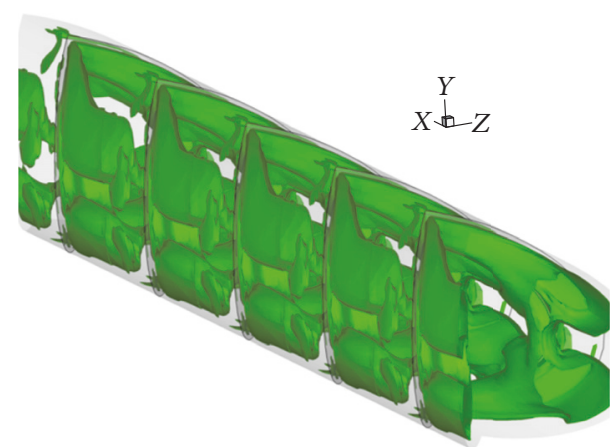

(a)

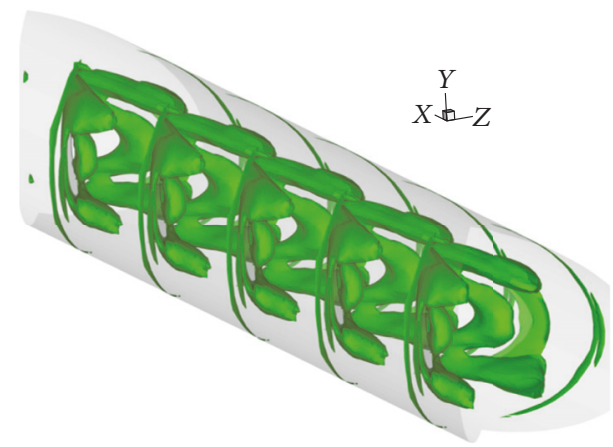

(c)

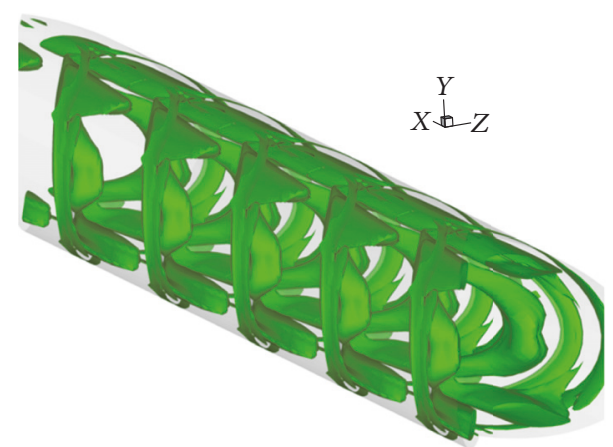

(b)

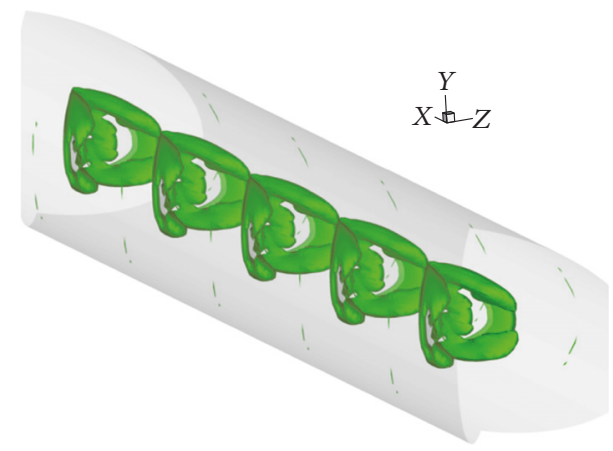

(d)

Figure 11: Iso-surface at $\lambda_{2}=-2500$ for (a) $B-1 U$, (b) $B-3 U$, (c) $B-5 U$, and (d) $B-7 U$ for $\operatorname{Re}=3000$.

flows are found in all planes of the tube heat exchanger. The eight small vortices are created at the second and third planes $(x / D=2.25$ and 3.5$)$ for $B-3 D$. $B-1 D$ provides the counterrotating flow with common-flow-up, while $B-3 D, B$ $5 D$, and $B-7 D$ produce the reverse rotational flow when considered at the lower pair of the vortex flow. Figure 13 presents the streamlines in $y-z$ planes for $B-1 U, B-3 U, B-5 U$, and $B-7 U$ at $x / D=1,2.25,3.5,4.75$, and 6 of $\operatorname{Re}=3000$. The general flow structure of the $\mathrm{V}$-upstream case is similar to the $\mathrm{V}$-Downstream case. The four core vortex flows are created in all cases, except for $B-3 U$. The eight vortices are found at $x / D=1,2.25,4.75$, and 6 of $B-3 U . B-1 U$ generates the counterrotating flow with common-flow-down, while $B-7 U$ creates the opposite flow rotation. In addition, the presence of the gap between the $\mathrm{V}$-orifices and tube wall is a reason for the change of the flow structure and vortex strength.

The heat transfer behaviors in the test section are described by the temperature distributions in $y-z$ planes and local Nusselt number distributions on the tube wall. Figure 14 shows the temperature contours in $y-z$ planes for $B-1 D$, $B-3 D, B-5 D$, and $B-7 D$ at $\operatorname{Re}=3000$. The disturbance of the thermal boundary layer is found at the upper-lower points of $B-3 D, B-5 D$, and $B-7 D$, except for $B-1 D$. The red layer of the temperature contours performs higher when the gap spacing ratio increased. The disruption of the thermal boundary layer is detected in the left-right parts of the planes for $B-1 D$. The difference location of the thermal disturbance is due to the different flow structure.
Figure 15 reports the temperature distributions in $y-z$ planes of $B-1 U, B-3 U, B-5 U$, and $B-7 U$ at $\operatorname{Re}=3000$. The best thermal disturbance is found in the left-right curves of the tube planes, except for $B-1 U$. The enhancement of the gap value provides lower strength of the vortex flow. The upper-lower points are disturbed by the vortex flow of $B-1 U$. Additionally, the reduction of the gap spacing results in the increasing vortex strength.

The local Nusselt number distributions on the tube wall of the tube heat exchanger inserted with $\mathrm{V}$-orifices for V-tip pointing downstream are displayed in Figure 16. The increasing $B R$ and reducing gap spacing result in the enhancing heat transfer rate. The peak of heat transfer regime is found in the left-right parts for $g / D \leq 0.05$ but is found in the upper-lower parts for $g / D>0.05$. Figure 17 presents $\mathrm{Nu}_{x}$ contours for the tube heat exchanger inserted with $\mathrm{V}$ orifices of upstream arrangement. The highest heat transfer regions are detected at the side parts of the tube wall, except for $g / D=0$. The augmentation of the gap ratio leads to decrease in the Nusselt number.

In conclusion, the space between $\mathrm{V}$-orifices and tube wall is important factor for flow structure. The spacing can convert the rotational vortex flow that is reason for the difference of the heat transfer regime.

4.4. Performance Analysis. The plots of $\mathrm{Nu} / \mathrm{Nu}_{0}$ with $\mathrm{Re}$ are reported in Figures 18-20 for $\mathrm{BR}=0.1,0.15$, and 0.2 , respectively. In general, $\mathrm{Nu} / \mathrm{Nu}_{0}$ tends to slightly decrease 
$x / D=1$
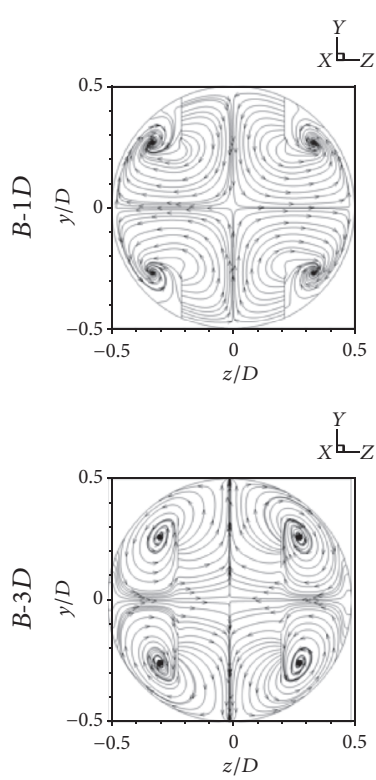

$x^{\stackrel{Y}{L}-Z}$
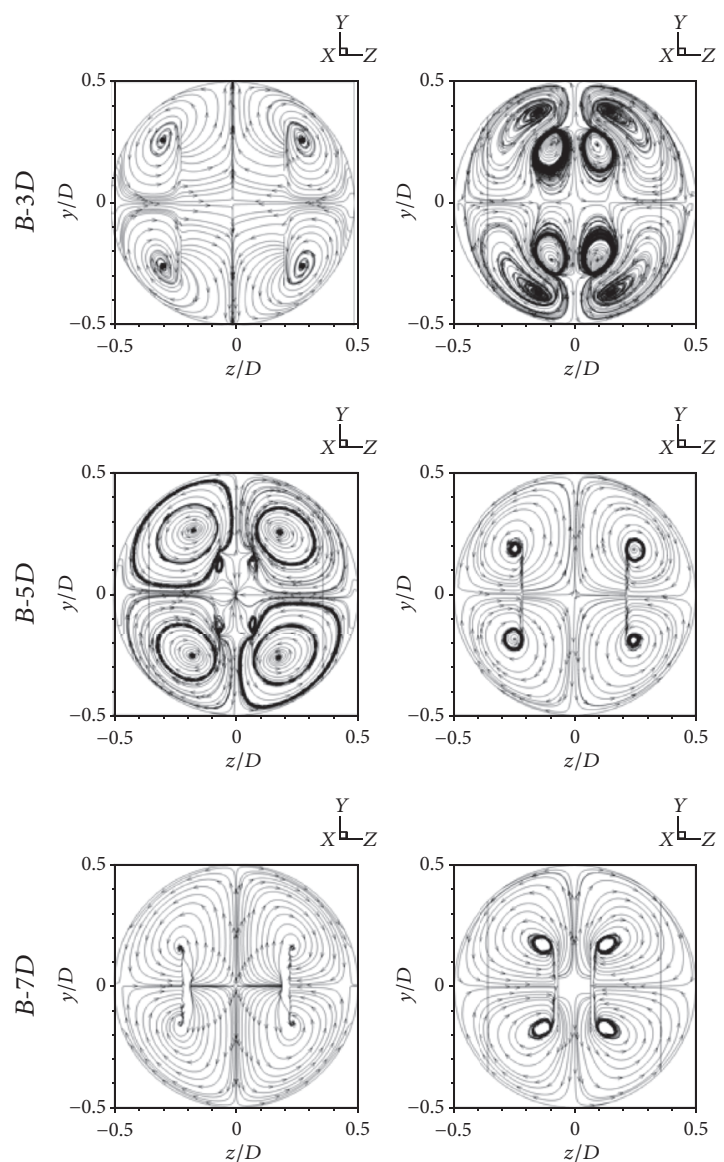

$x / D=2.25$

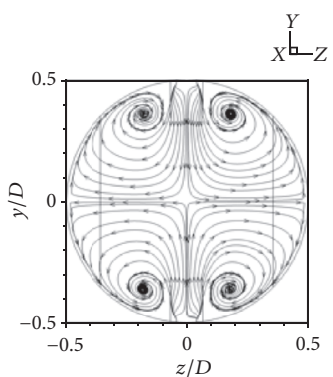

$x^{Y}-Z$
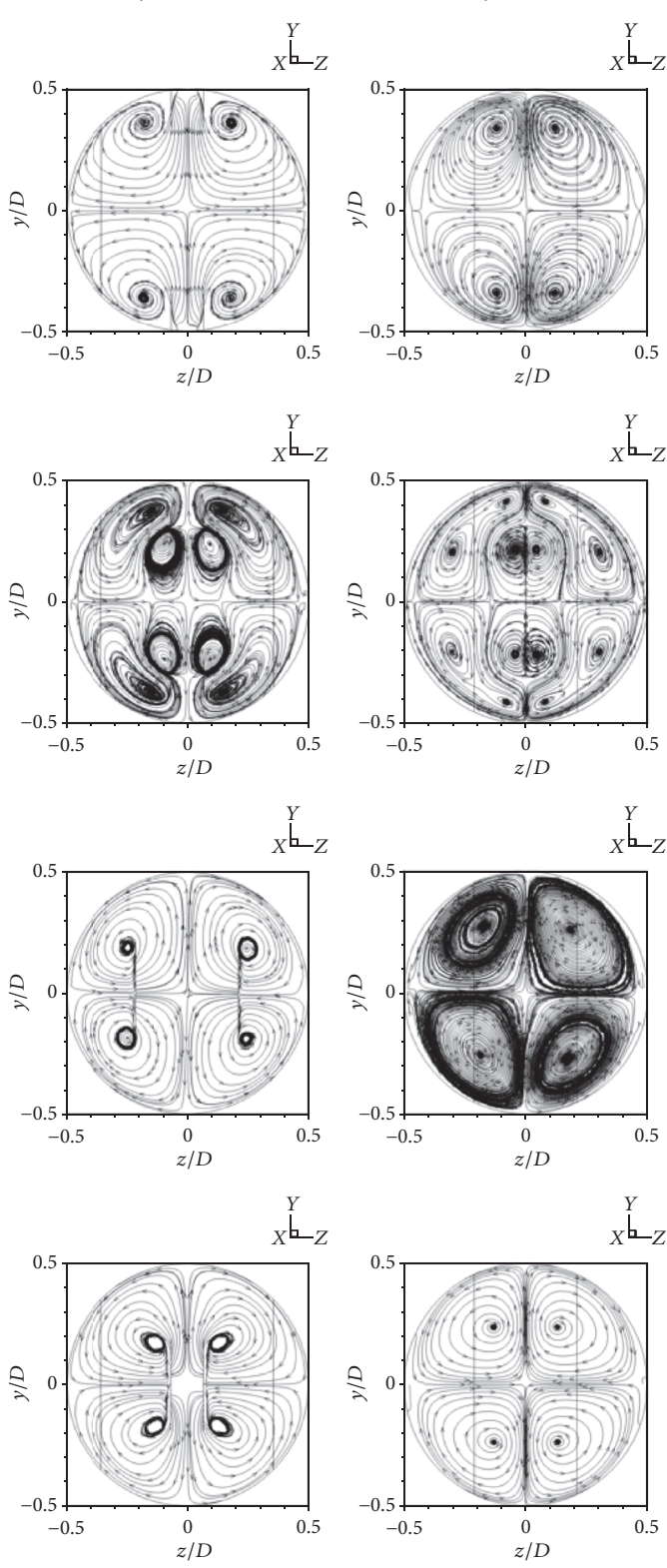

$x / D=4.75$

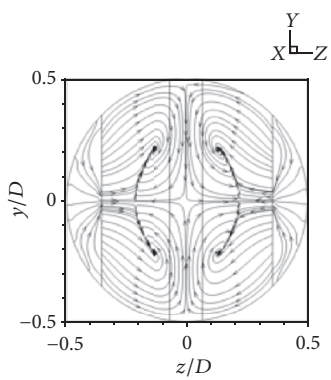

$x^{Y}-Z$
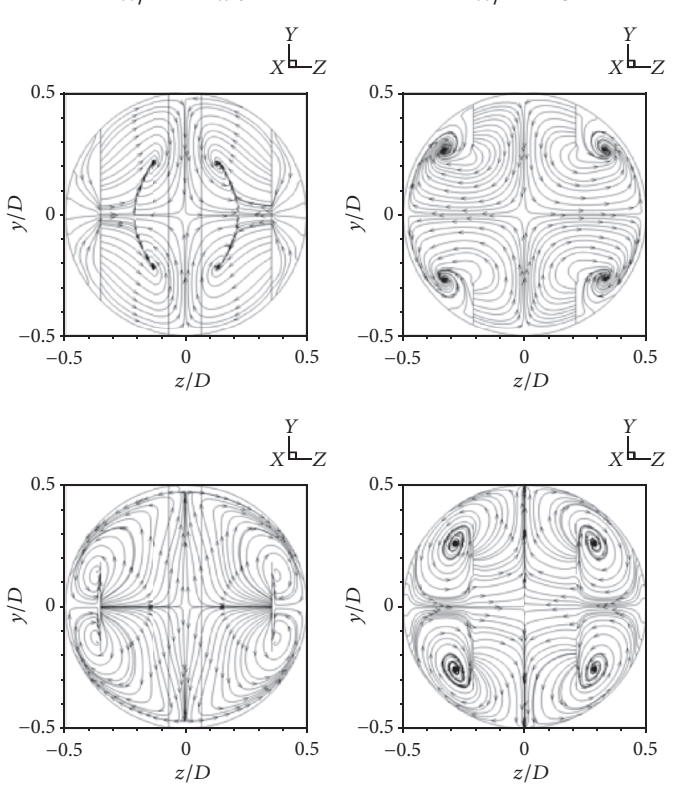

$x^{Y}-Z$
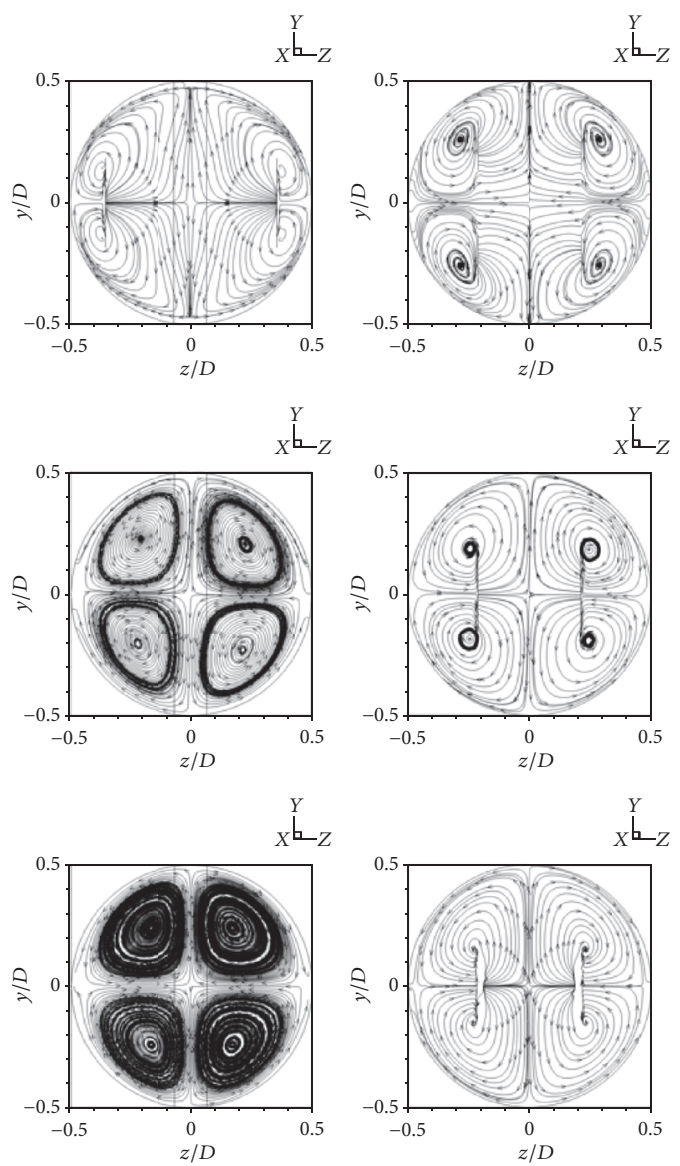

FIGURE 12: Streamlines in $y-z$ plane for downstream arrangement at $\operatorname{Re}=3000$.

with increasing the Reynolds number. The insertion of the $\mathrm{V}$ orifices in the tube heat exchanger gives higher heat transfer rate than the smooth tube $\left(\mathrm{Nu} / \mathrm{Nu}_{0}>1\right)$.

As Figure 18(a), the maximum Nusselt number is found at $A-1 D$, while the lowest value is detected at $A-8 D$. The nonlinearization decrease of the Nusselt number is found due to the reduction of the gap ratio. It is interesting to note that $A$ $2 D$ gives lower heat transfer rate than $A-1 D$ around $25 \%$, while $A-3 D, A-4 D, A-5 D, A-6 D, A-7 D$, and $A-8 D$ provide lower values than $A-1 D$ around $1.18 \%, 1.18 \%, 4.72 \%, 10.38 \%, 18.56 \%$, and $34.20 \%$, respectively. The maximum Nusselt number is about $4.24,3.15,4.19,4.19,4.04,3.80,3.41$, and 2.79 times above the smooth tube at $\mathrm{Re}=3000$. Figure $18(\mathrm{~b})$, the highest heat transfer rate around 6.32, is clearly obtained at $A-1 U$ for
$\mathrm{Re}=3000 . A-2 U, A-3 U, A-4 U, A-5 U, A-6 U, A-7 U$, and $A-8 U$ give lower Nusselt number than $A-1 U$ around $53 \%, 47.63 \%$, $43.99 \%, 46.52 \%, 50.63 \%, 55.22 \%$, and $62.5 \%$, respectively. The similar trends of the Nusselt number ratio are found in cases $B$ and $C$. In the range studies, the heat transfer rate is found to be around 2.25-4.50, 1.84-6.32, 3.00-5.03, 2.25-6.00, 3.65-6.70, and 2.75-8.25 times higher than that in the smooth tube for $A-D, A-U, B-D, B-U, C-D$, and $C-U$, respectively.

Figures 21-23 report the relations of $f / f_{0}$ with the Reynolds number at various cases. Generally, the use of the $\mathrm{V}$-orifice in the heating system yields higher pressure loss than the smooth circular tube in all cases $\left(f / f_{0}>1\right)$. The enhancement of the pressure loss is found when increasing the Reynolds number. The rise of the gap spacing helps 

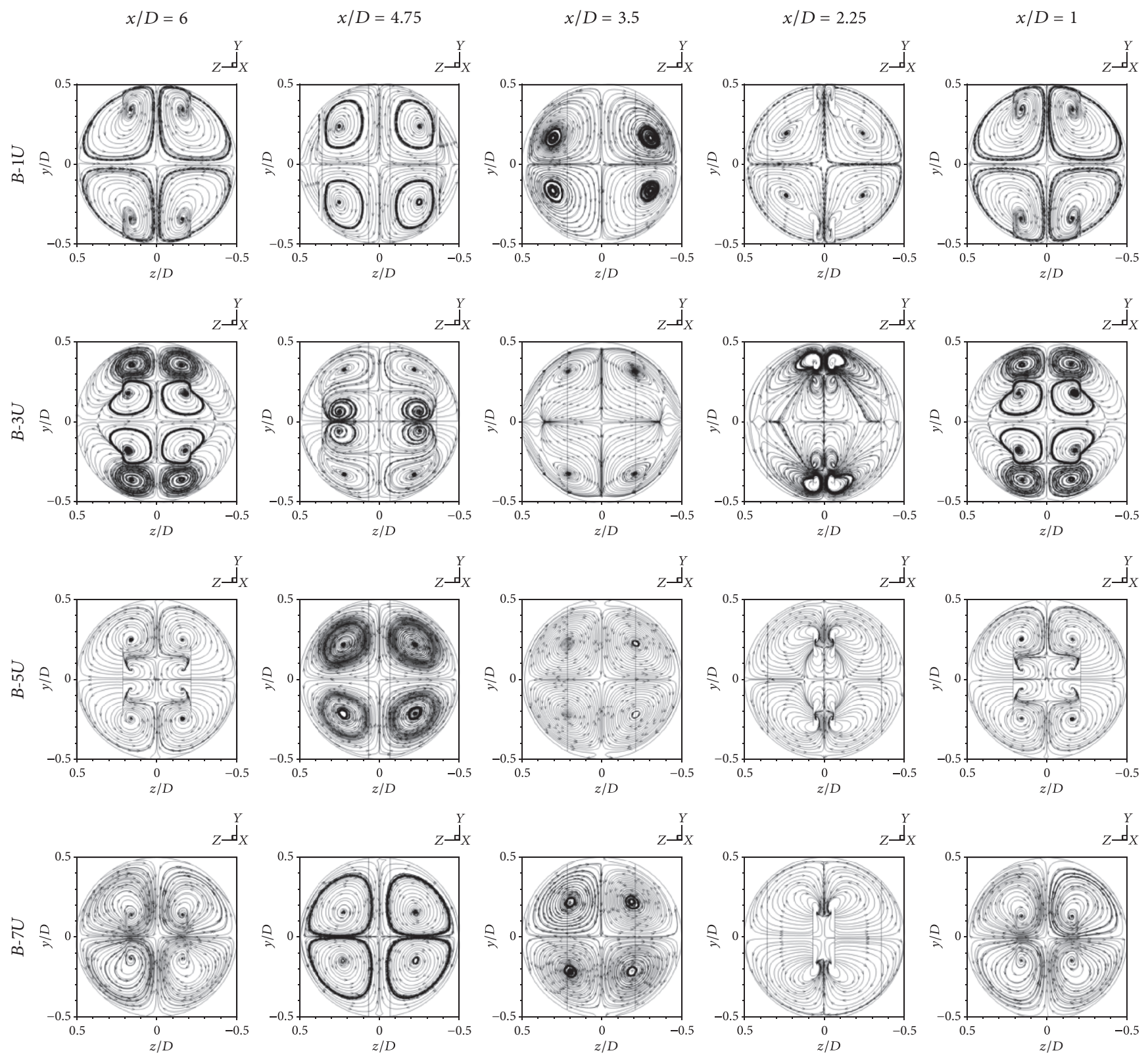

FIGURE 13: Streamlines in $y$ - $z$ plane for upstream arrangement at $\operatorname{Re}=3000$.

to reduce the friction loss, except for $A-1 D$ to $A-4 D$ (see Figure 21(a)). The reduction of the flow area results in the higher friction loss, especially at $C-D$ and $C-U$ cases. $f / f_{0}$ is around 5.9-22, 4.2-34, 12-61, 7.5-77.5, 20-170, and 15-270 for $A-D, A-U, B-D, B-U, C-D$, and $C-U$, respectively.

Figures 24-26 present the variations of the thermal enhancement factor, TEF, with the Reynolds number. In general, the TEF tends to decrease with the rise of the Reynolds number. The optimum TEF at various BRs and arrangements is concluded as Table 3. It is interesting to note that the gap spacing helps to optimize the thermal enhancement factor at high $\mathrm{BR}, \mathrm{BR}=0.15$ and 0.20 .
TABLE 3: The maximum TEF for each BR and arrangement.

\begin{tabular}{lc}
\hline Case studied & $\mathrm{TEF}_{\max }$ \\
\hline$A-1 D$ & 1.8 \\
$A-1 U$ & 2.25 \\
$B-5 D, B-6 D$ & 1.75 \\
$B-1 U$ & 1.54 \\
$C-5 D$ & 1.75 \\
$C-6 U$ & 1.45 \\
\hline
\end{tabular}

Figures 27(a), 27(b), and 27(c) depict the relations between $\mathrm{Nu} / \mathrm{Nu}_{0}$ and $g / D$ for $\mathrm{BR}=0.1,0.15$, and 0.2 , 
$x / D=1$
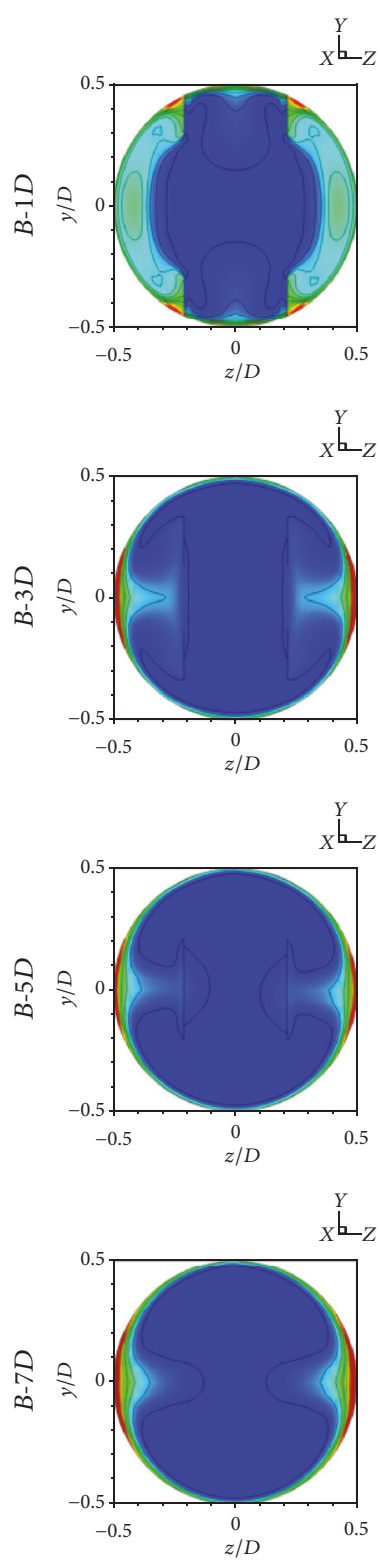

$x / D=2.25$
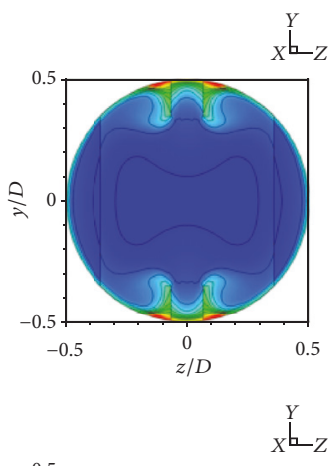
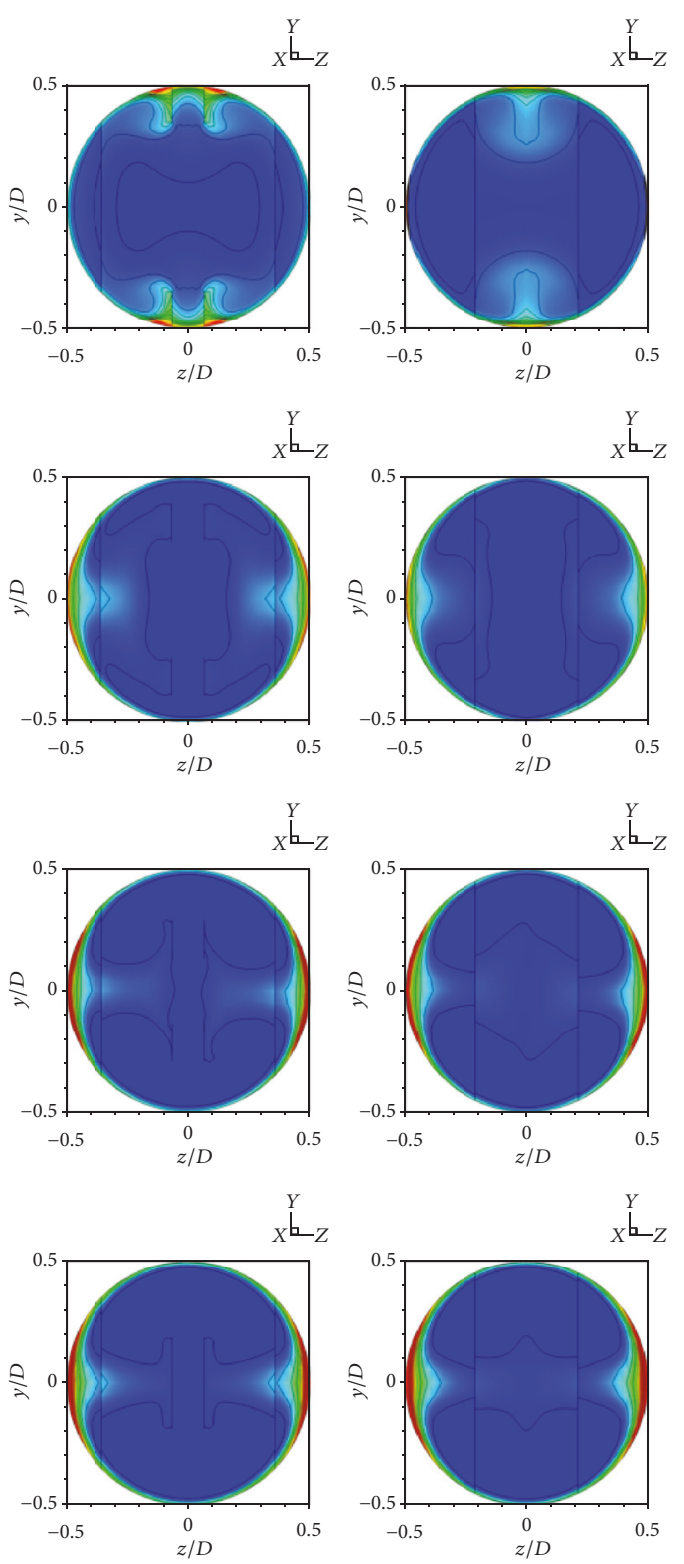

$x / D=3.5$
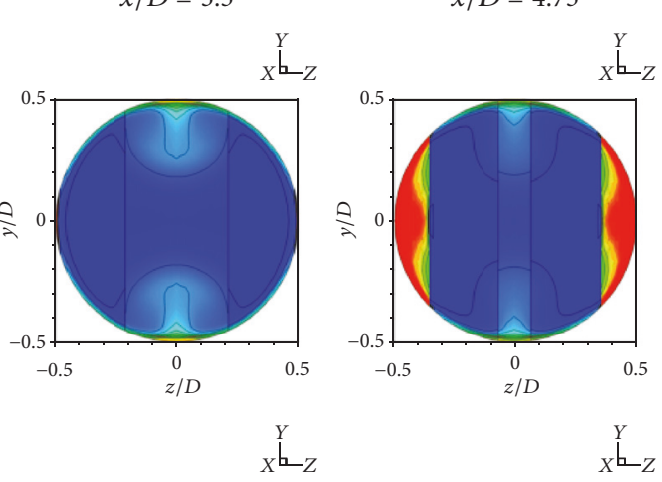

$x / D=4.75$
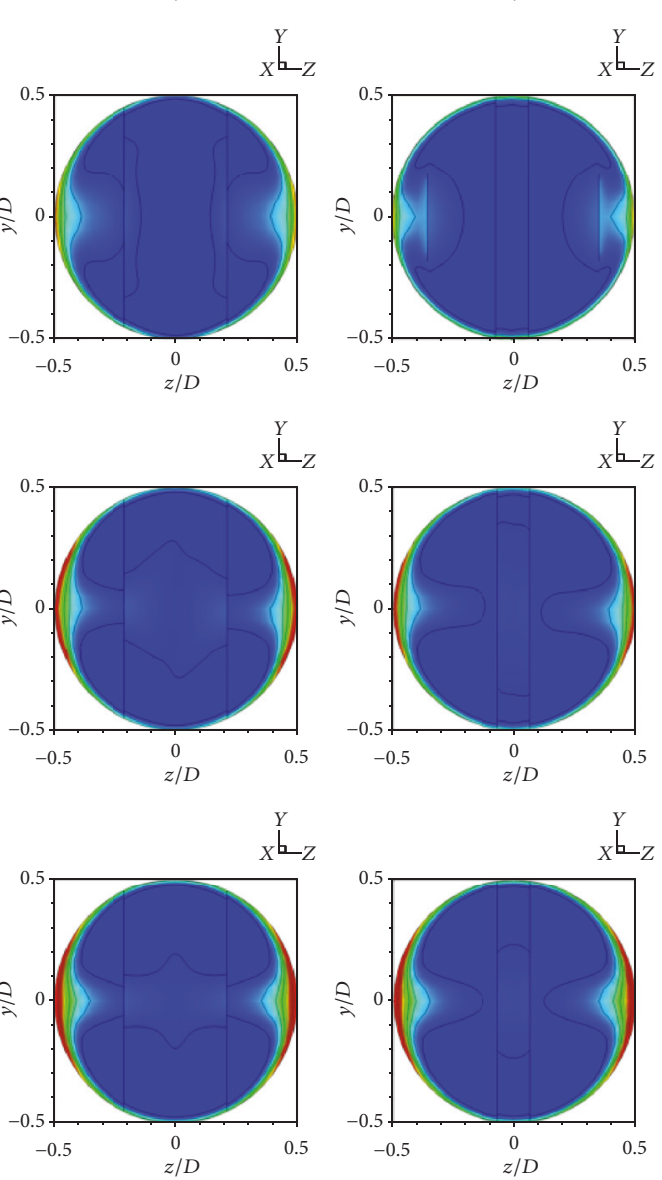

$x / D=6$
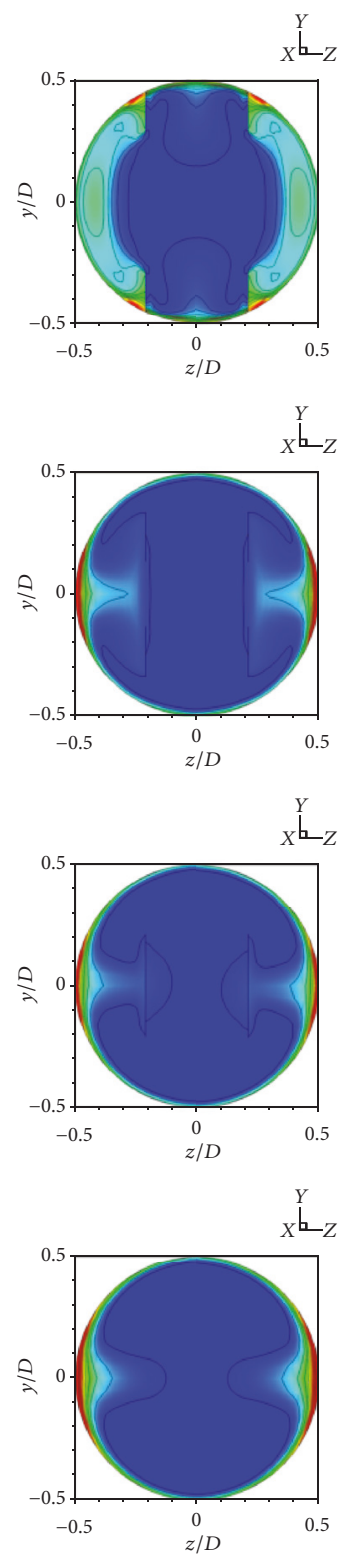

FIgURE 14: Temperature distributions in $y$ - $z$ plane for downstream arrangement at $\operatorname{Re}=3000$.

respectively. The decrement of $\mathrm{Nu} / \mathrm{Nu}_{0}$ is found when $g / D>$ 10 and in the range $0<g / D<5$ for downstream arrangement. For upstream arrangement, $0<g / D<5, \mathrm{Nu} / \mathrm{Nu}_{0}$ extremely decreases. Figures 28(a), 28(b), and 28(c) present the variations of $f / f_{0}$ with $g / D$ for $B R=0.1,0.15$, and 0.2 , respectively. The gap ratio around $5 \%$ extremely helps to reduce the pressure loss, especially upstream arrangement.

\section{Conclusion}

The numerical investigations on turbulent forced convection and heat transfer behavior in the circular tube heat exchanger inserted with the $\mathrm{V}$-orifices are reported. The influences of the blockage ratio and gap ratio are examined for $\mathrm{Re}=3000-10,000$. The major outcomes are concluded as follows:

(i) The better heat transfer rate and thermal performance are found due to the vortex flows in the heating tube, created by the $\mathrm{V}$-orifices. The disturbance of the thermal boundary layer by the vortex flow is important reason for the heat transfer augmentation.

(ii) The gap spacing between $\mathrm{V}$-orifices and tube wall is a cause for the change of the flow topology that leads to a variation of the heat transfer behavior. The optimum gap spacing may lead to the optimum thermal enhancement factor. 

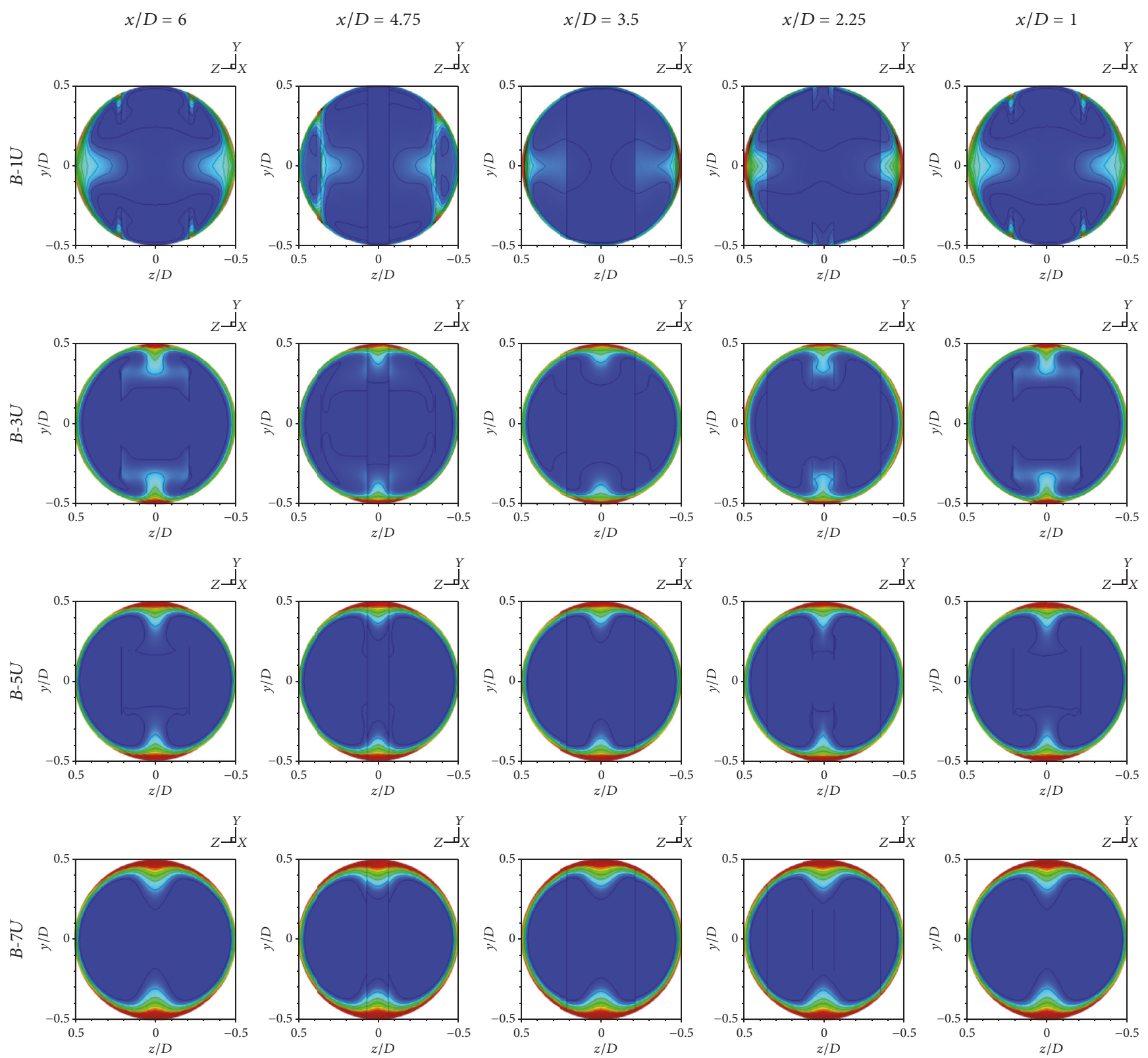

FIGURE 15: Temperature distributions in $y-z$ plane for upstream arrangement at $\operatorname{Re}=3000$.
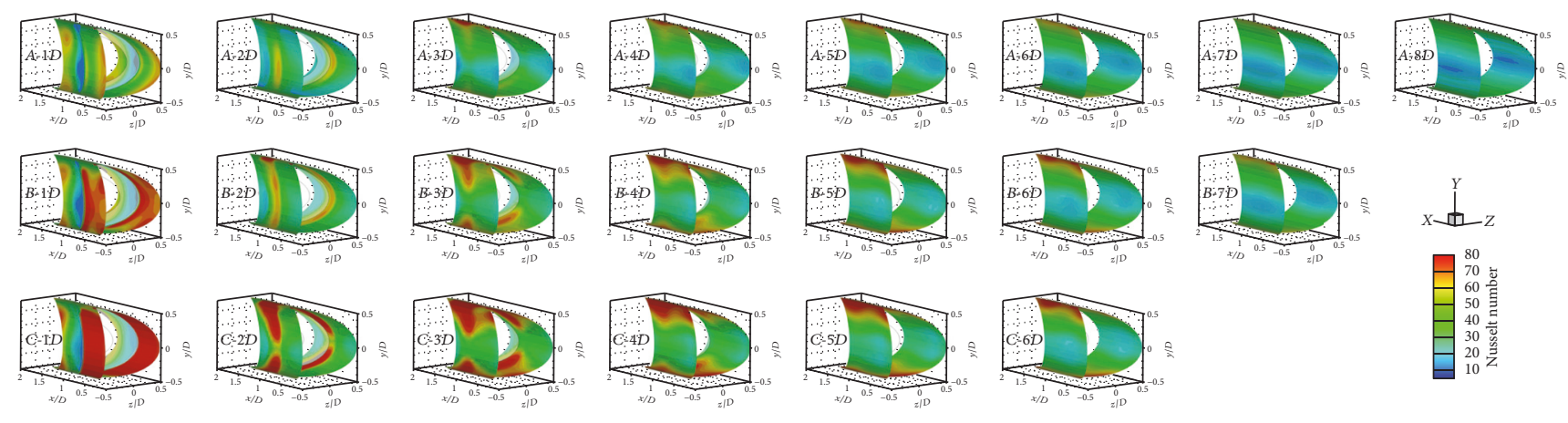

FIGURE 16: Local Nusselt number distributions on the tube wall for downstream arrangement at $\operatorname{Re}=3000$. 

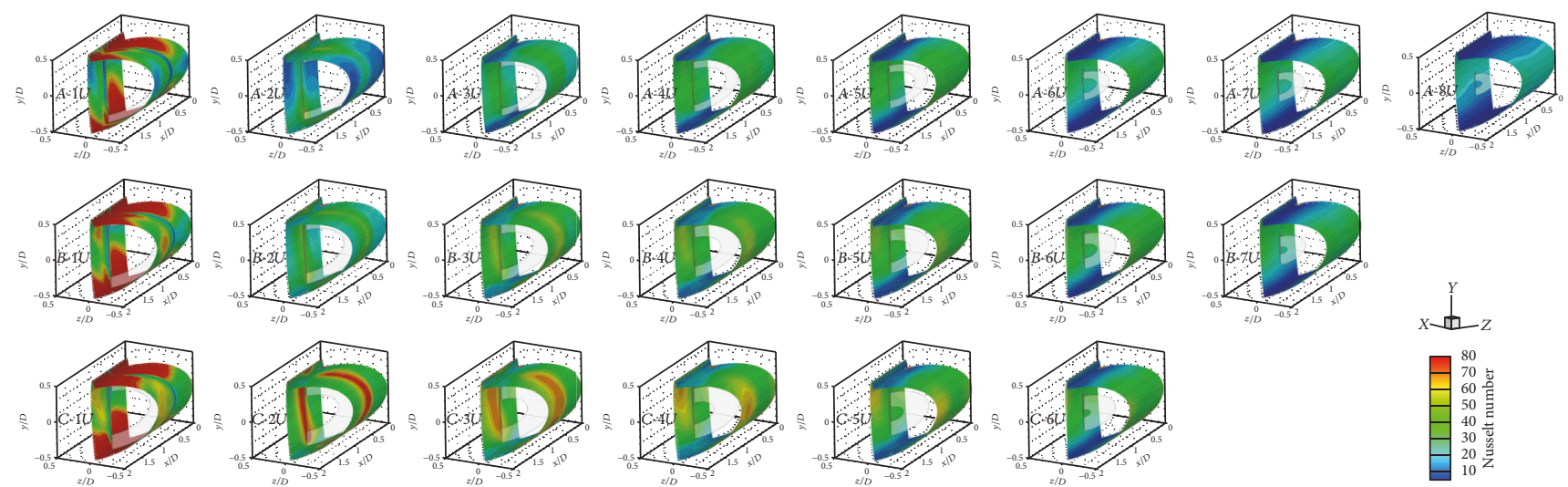

FIGURE 17: Local Nusselt number distributions on the tube wall for upstream arrangement at $\operatorname{Re}=3000$.

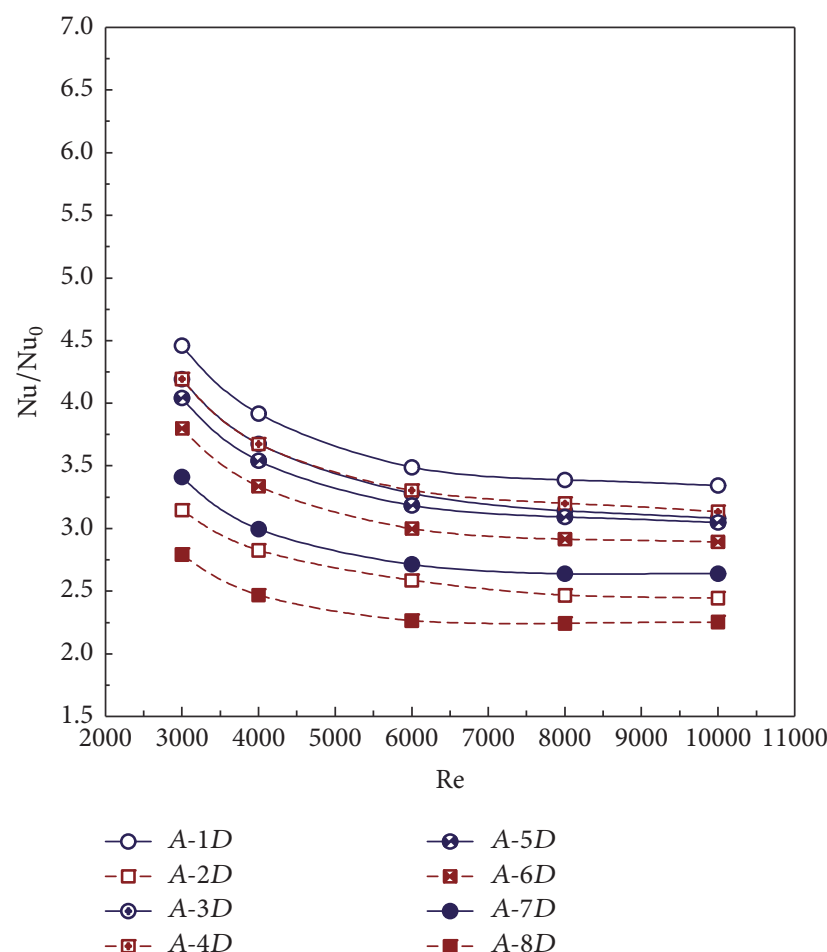

(a)

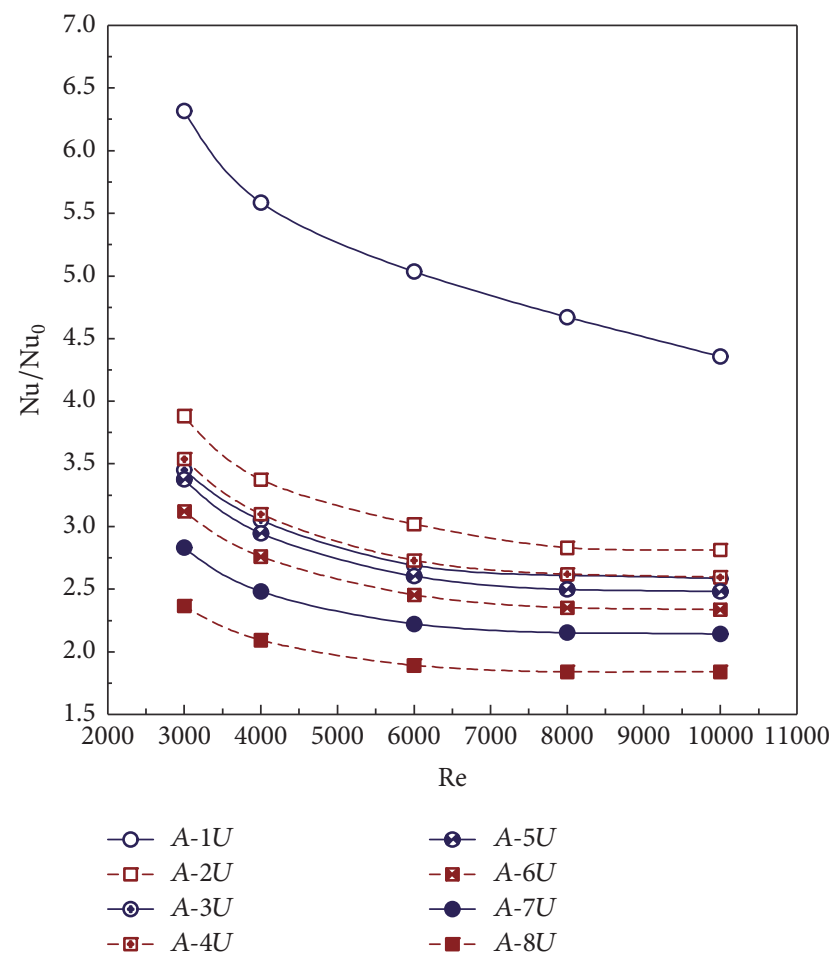

(b)

Figure 18: $\mathrm{Nu} / \mathrm{Nu}_{0}$ versus Re for (a) $A-D$ and (b) $A-U$.

(iii) In range investigations, the enhancements of the Nusselt number and friction factor are found to be highest around 8.26 and 270 times above the smooth tube, respectively. The maximum thermal enhancement factor is about 2.25.

\section{Nomenclature}

BR: Flow blockage ratio $(=b / D)$

$b$ : $\quad$ Orifice height, $\mathrm{m}$

$D$ : Diameter of tube

$f$ : Friction factor g: Gap spacing

$h$ : Convective heat transfer coefficient, $\mathrm{W} \mathrm{m}{ }^{-2} \mathrm{~K}^{-1}$

$k$ : Thermal conductivity, $\mathrm{W} \mathrm{m}^{-1} \mathrm{~K}^{-1}$

Nu: Nusselt number $(=h D / k)$

$P: \quad$ Distance between ribs

$p$ : Static pressure, $\mathrm{Pa}$

Pr: Prandtl number $(\mathrm{Pr}=0.707)$

PR: Pitch or spacing ratio $(=P / D)$

Re: Reynolds number $(=\rho \bar{u} D / \mu)$

$T$ : $\quad$ Temperature, $\mathrm{K}$ 

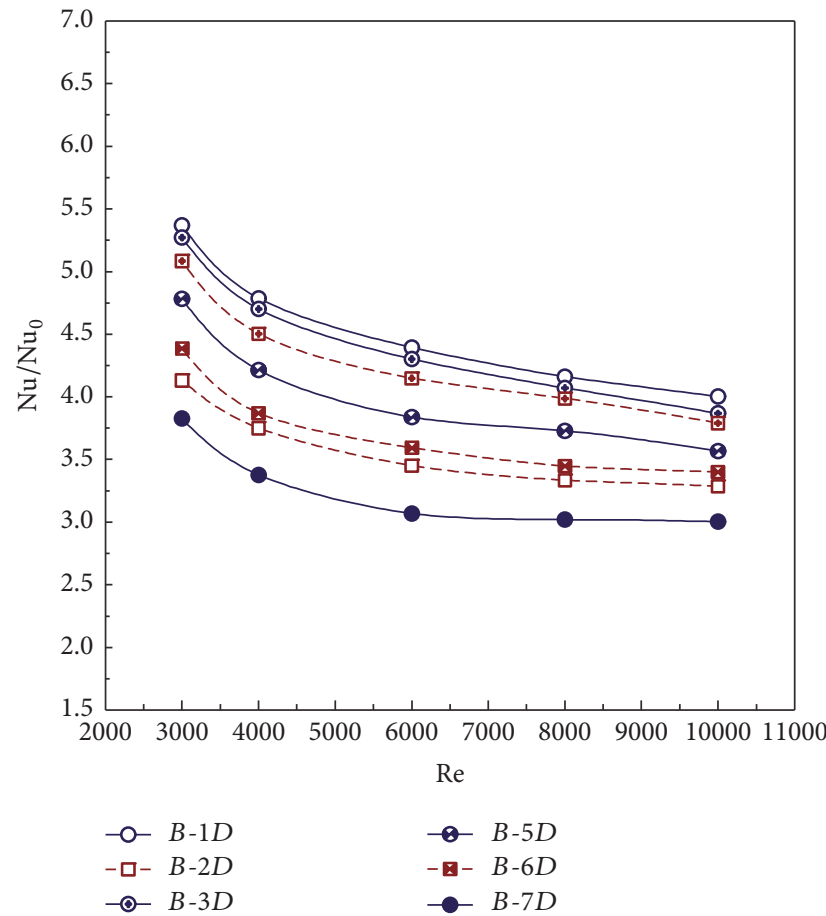

(a)
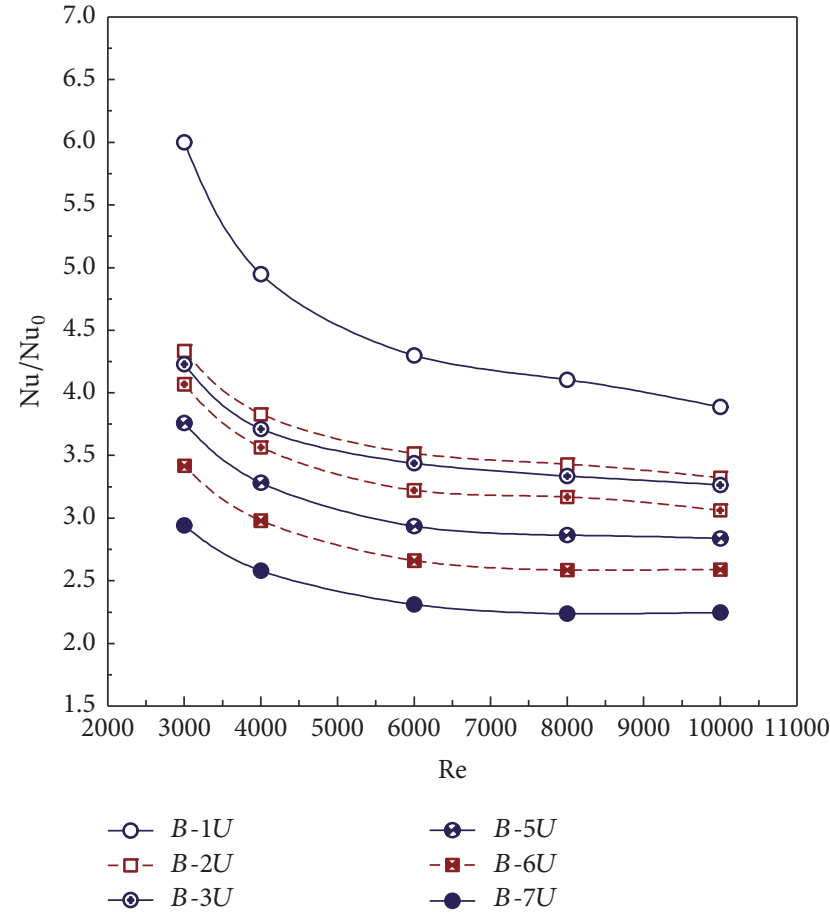

(b)

Figure 19: $\mathrm{Nu} / \mathrm{Nu}_{0}$ versus Re for (a) $B-D$ and (b) $B-U$.
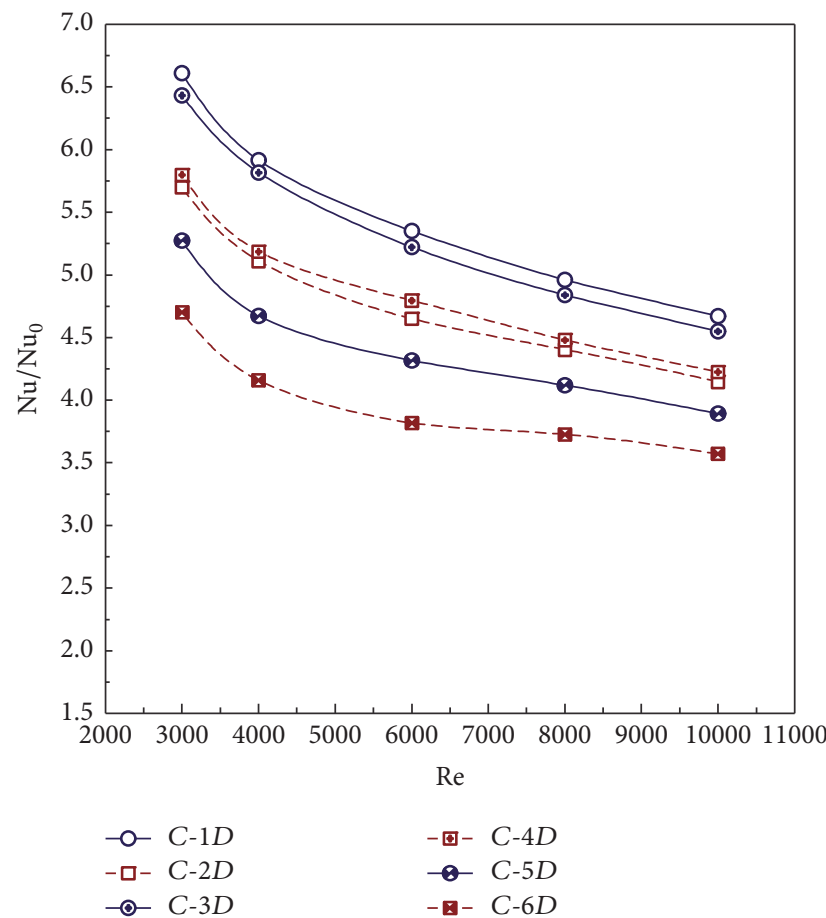

(a)
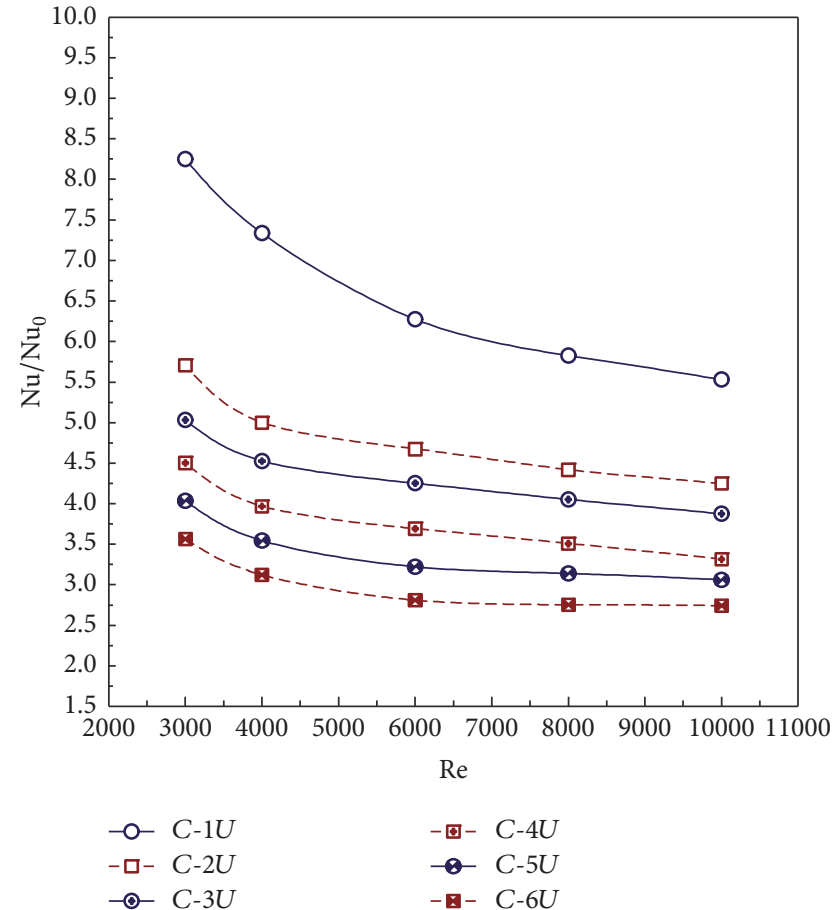

(b)

Figure 20: $\mathrm{Nu} / \mathrm{Nu}_{0}$ versus $\mathrm{Re}$ for (a) $C-D$ and (b) $C-U$. 

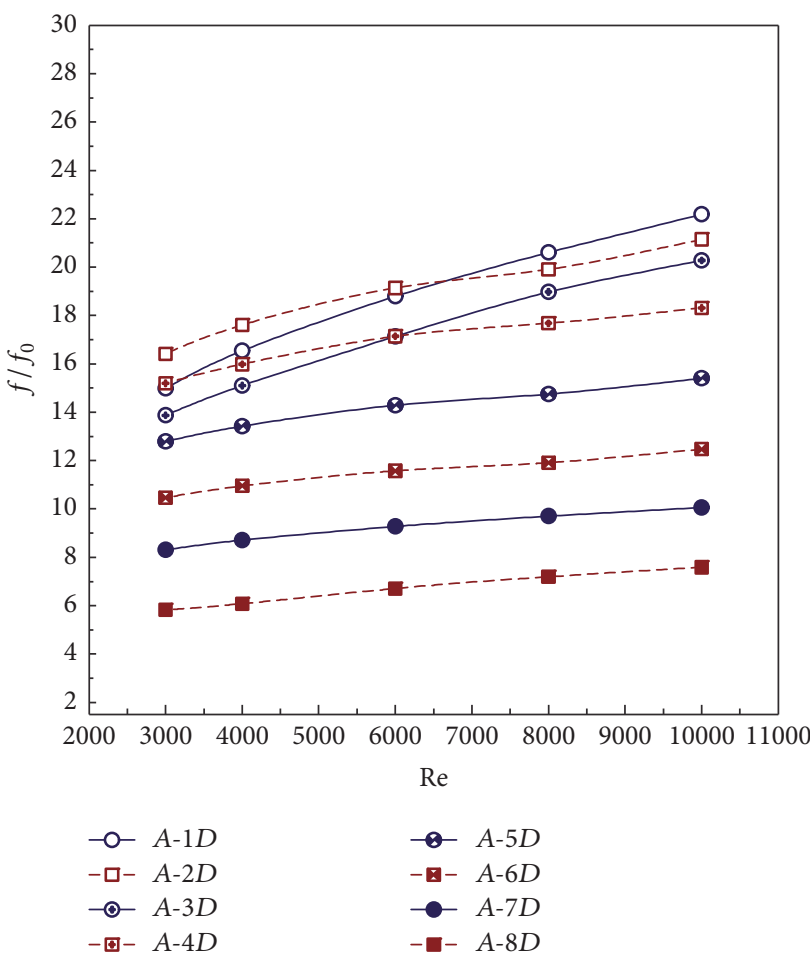

(a)
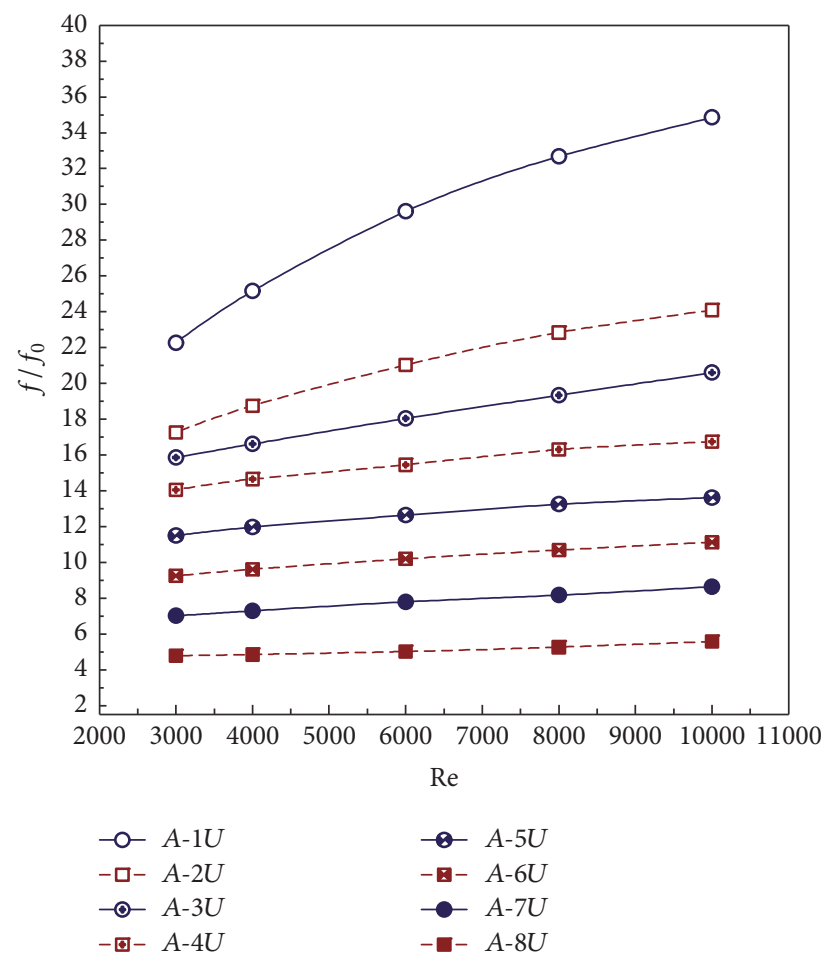

(b)

Figure 21: $f / f_{0}$ versus Re for (a) $A-D$ and (b) $A-U$.

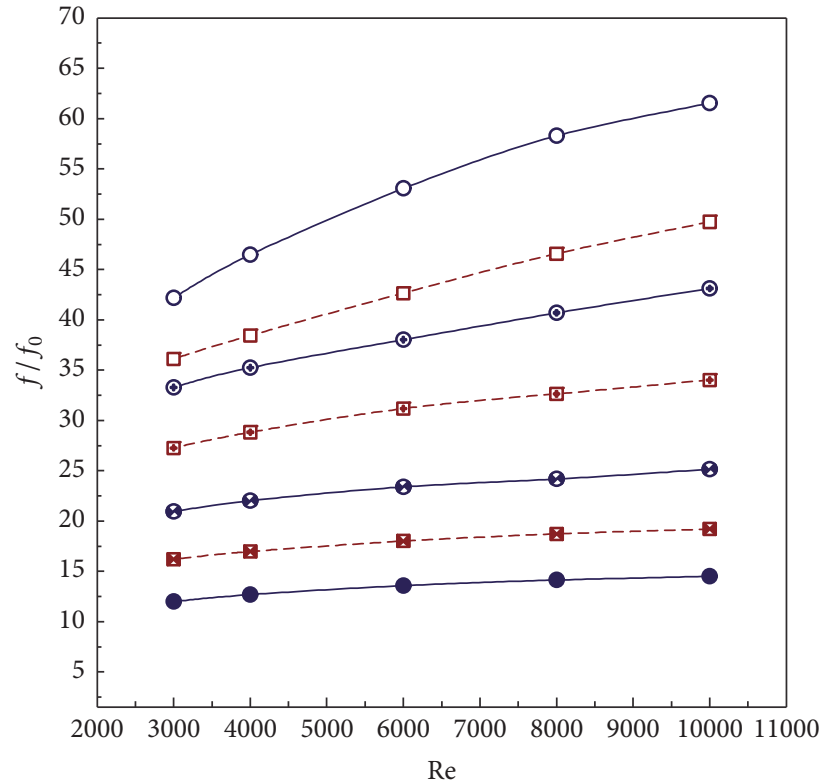

$-O-B-1 D$

$-\square-B-2 D$

- $B-3 D$

$-\square-B-4 D$
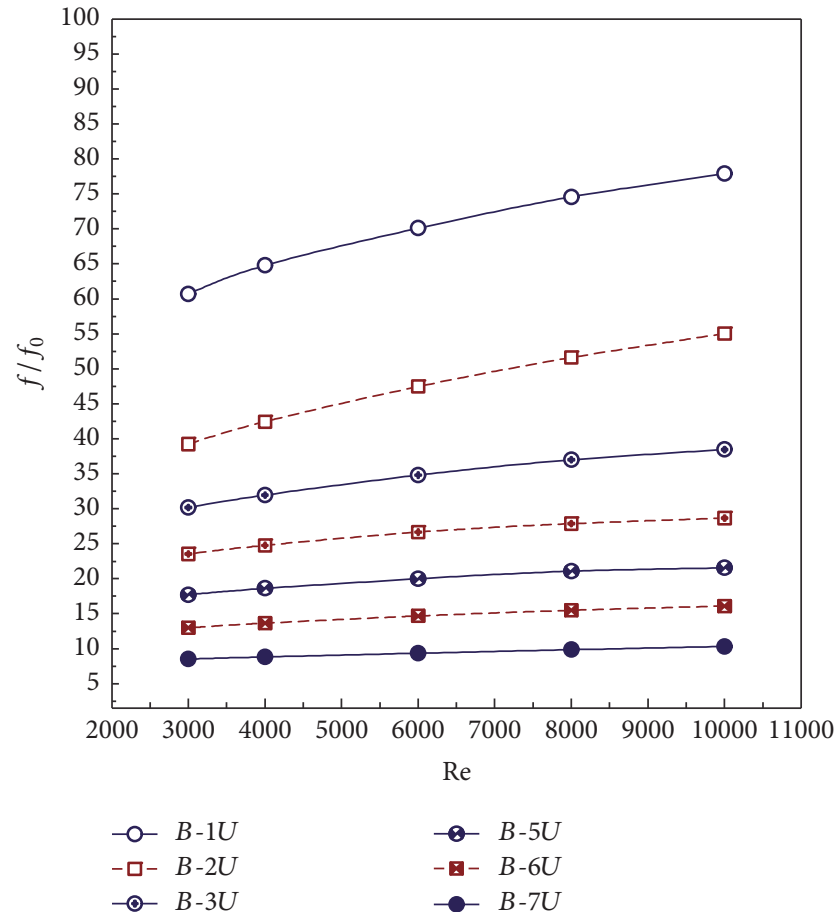

(b)
$B-7 U$ (a)

- $B-5 D$
- $-B-6 D$
$-0-7 D$

Figure 22: $f / f_{0}$ versus Re for (a) $B-D$ and (b) $B-U$. 


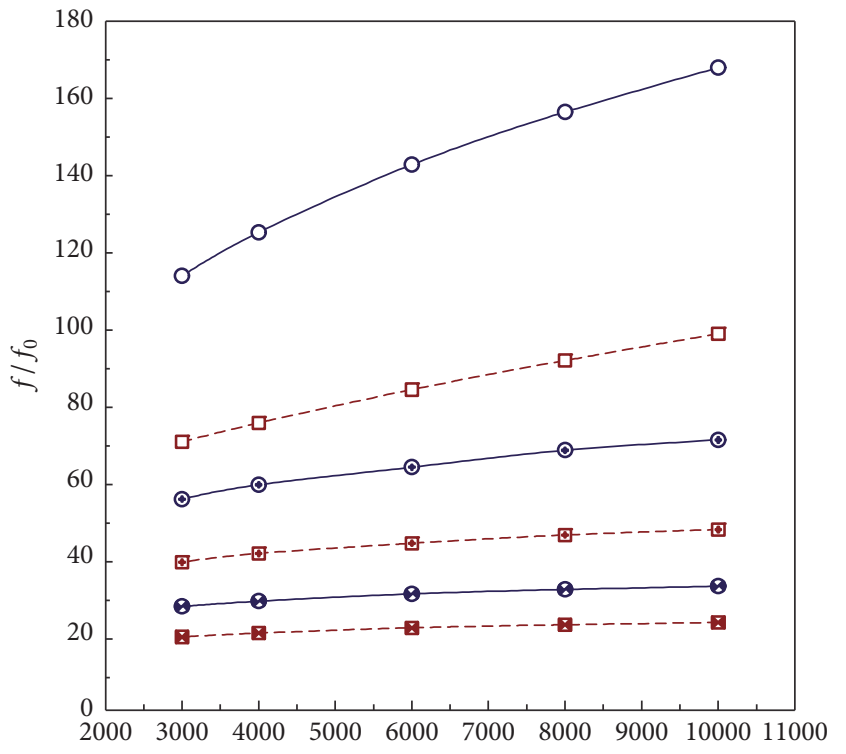

$\mathrm{Re}$

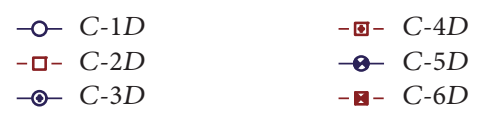

(a)

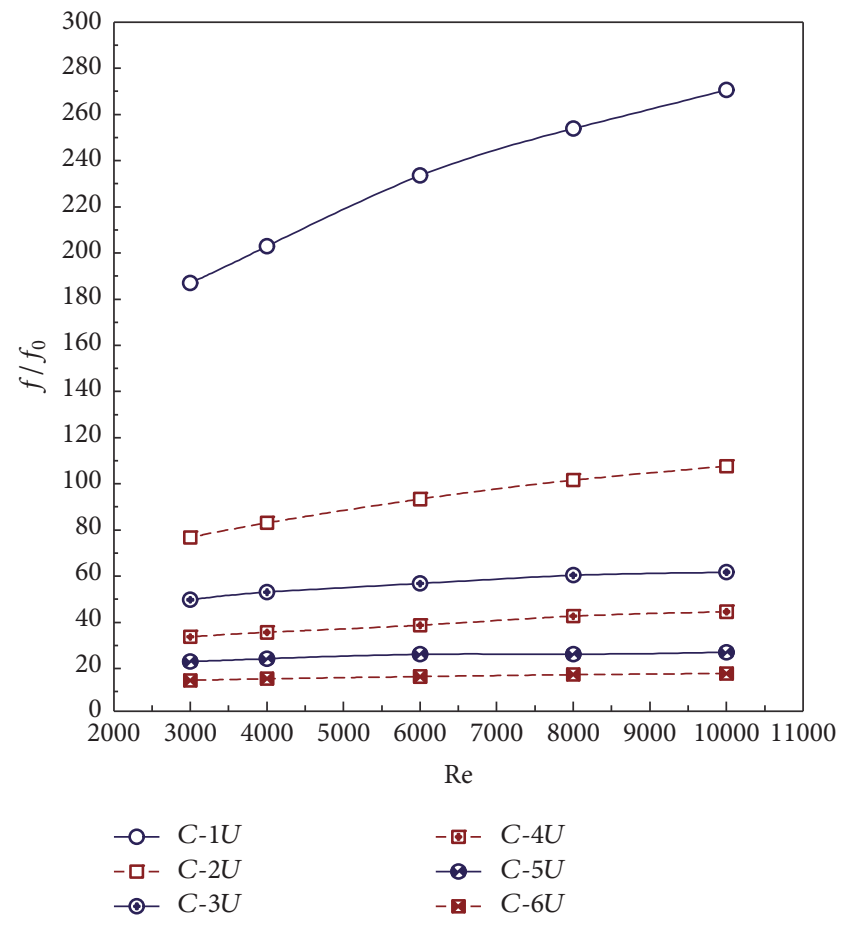

(b)

Figure 23: $f / f_{0}$ versus Re for (a) $C-D$ and (b) $C$ - $U$.
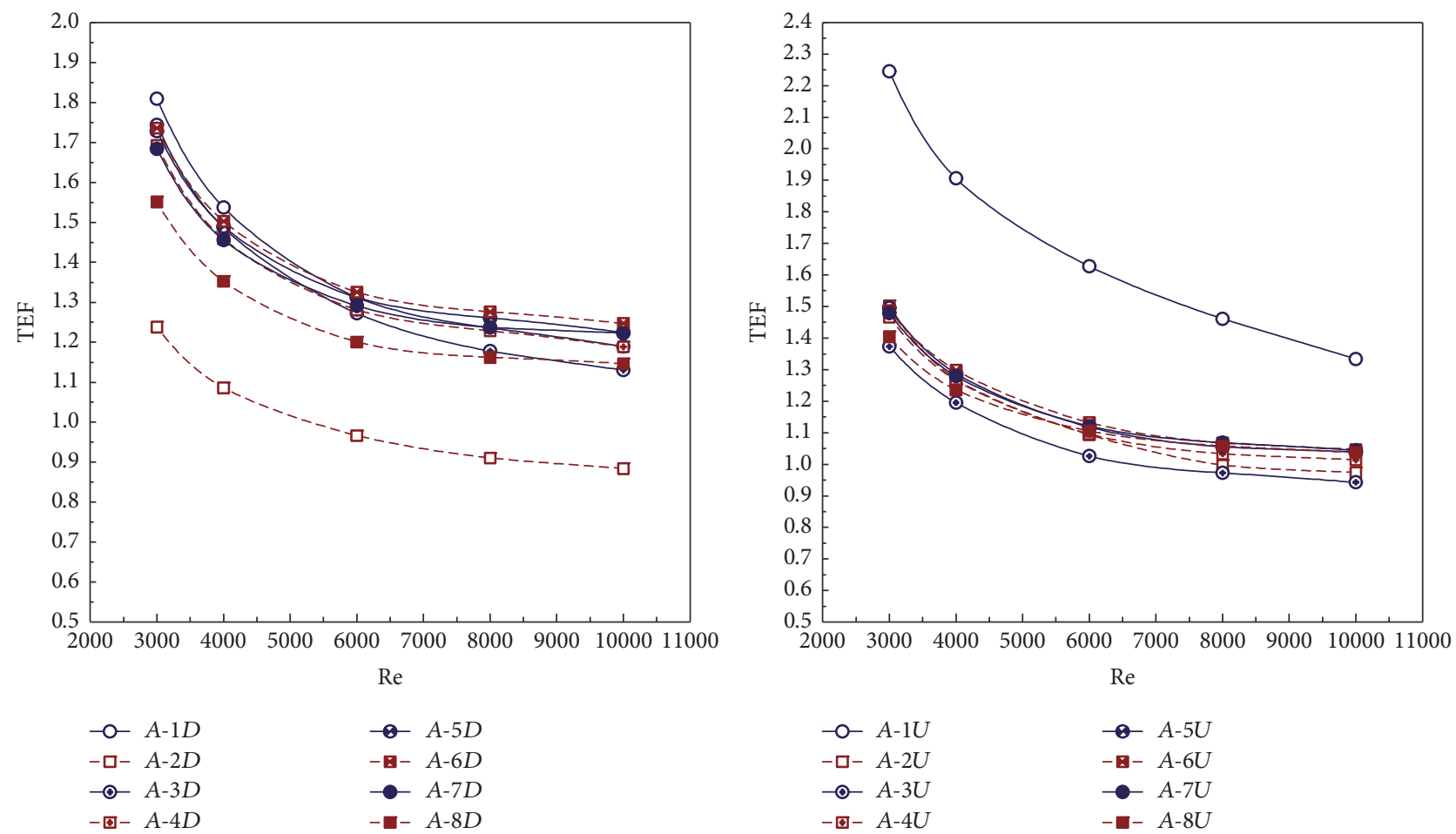

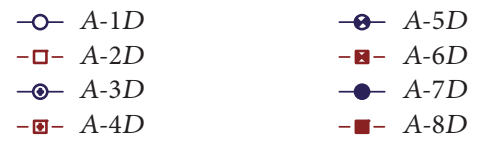

(a) (b)

Figure 24: TEF versus Re for (a) $A-D$ and (b) $A-U$. 


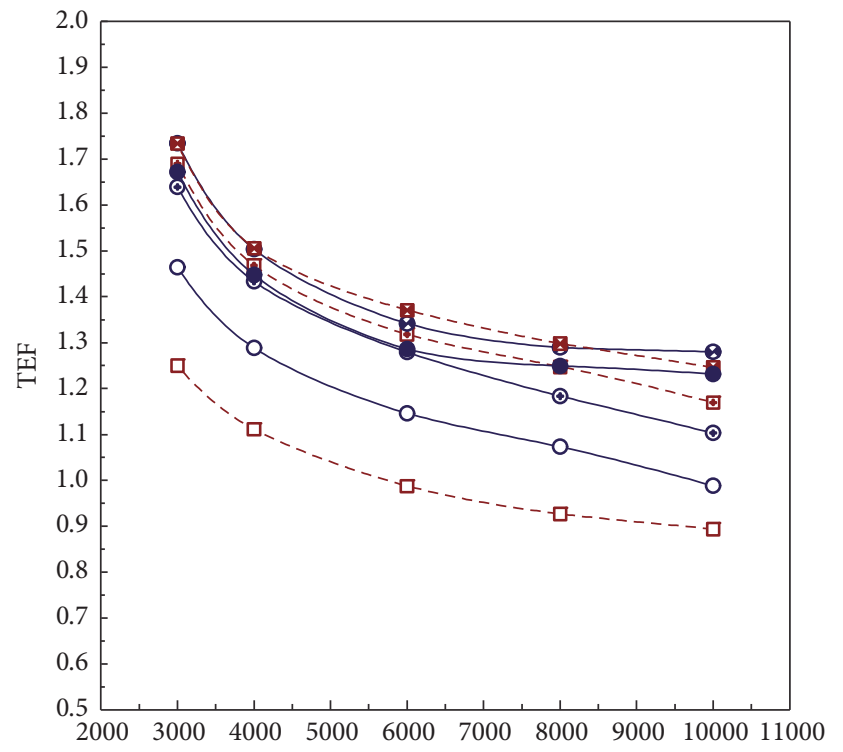

Re

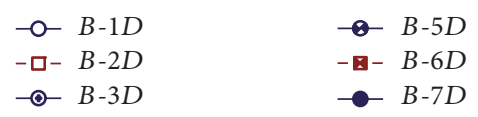

- $B-4 D$

(a)

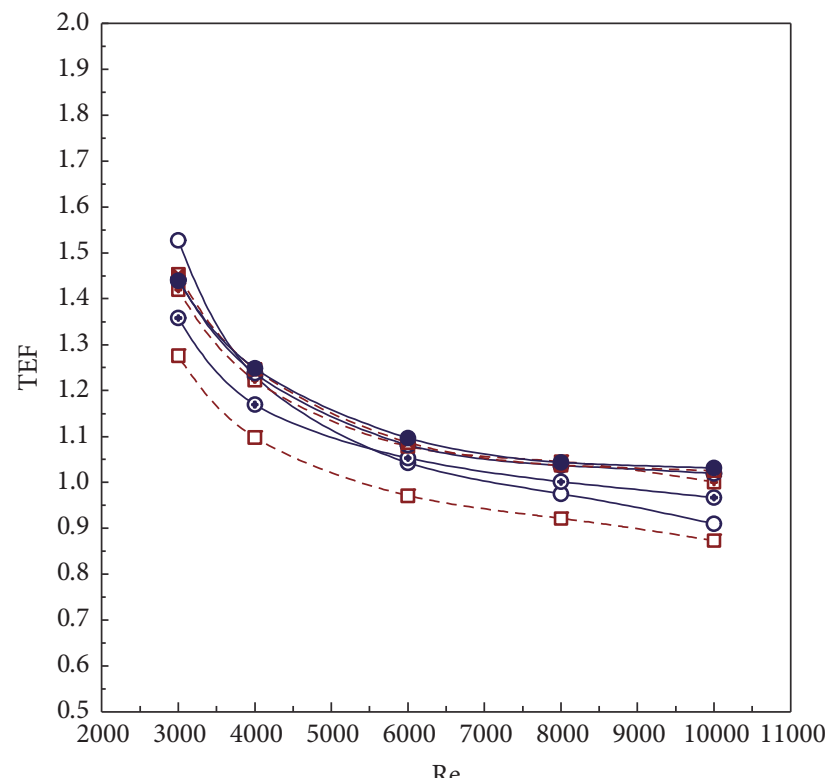

$-0-B-1 U$

$-\square-B-2 U$

$-\circ-3-3 U$

- 0 - B- $4 U$

-8- $B-5 U$

- - $B-6 U$

$\rightarrow B-7 U$

(b)

FIgURE 25: TEF versus Re for (a) $B-D$ and (b) $B-U$.

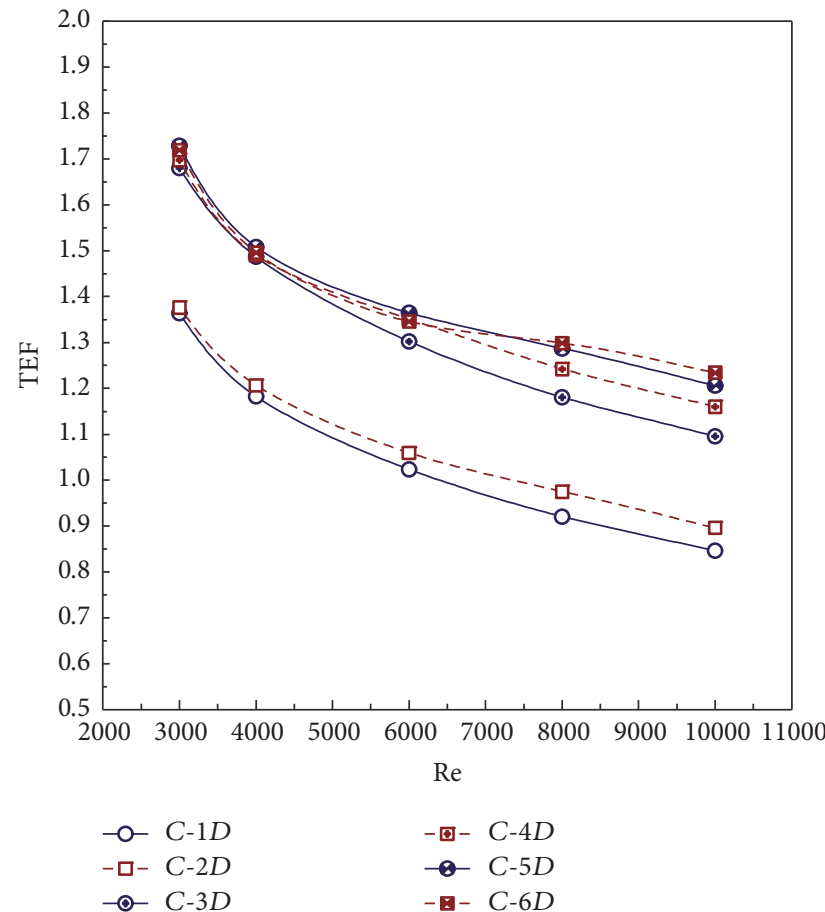

(a)

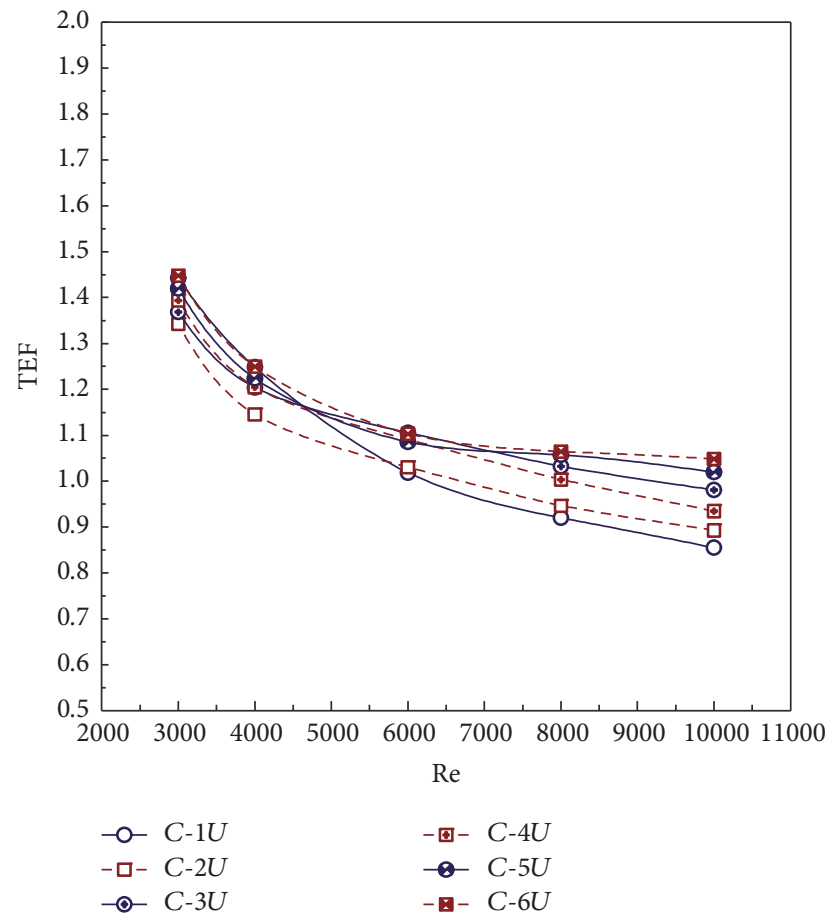

(b)

Figure 26: TEF versus Re for (a) $C-D$ and (b) $C$ - $U$. 

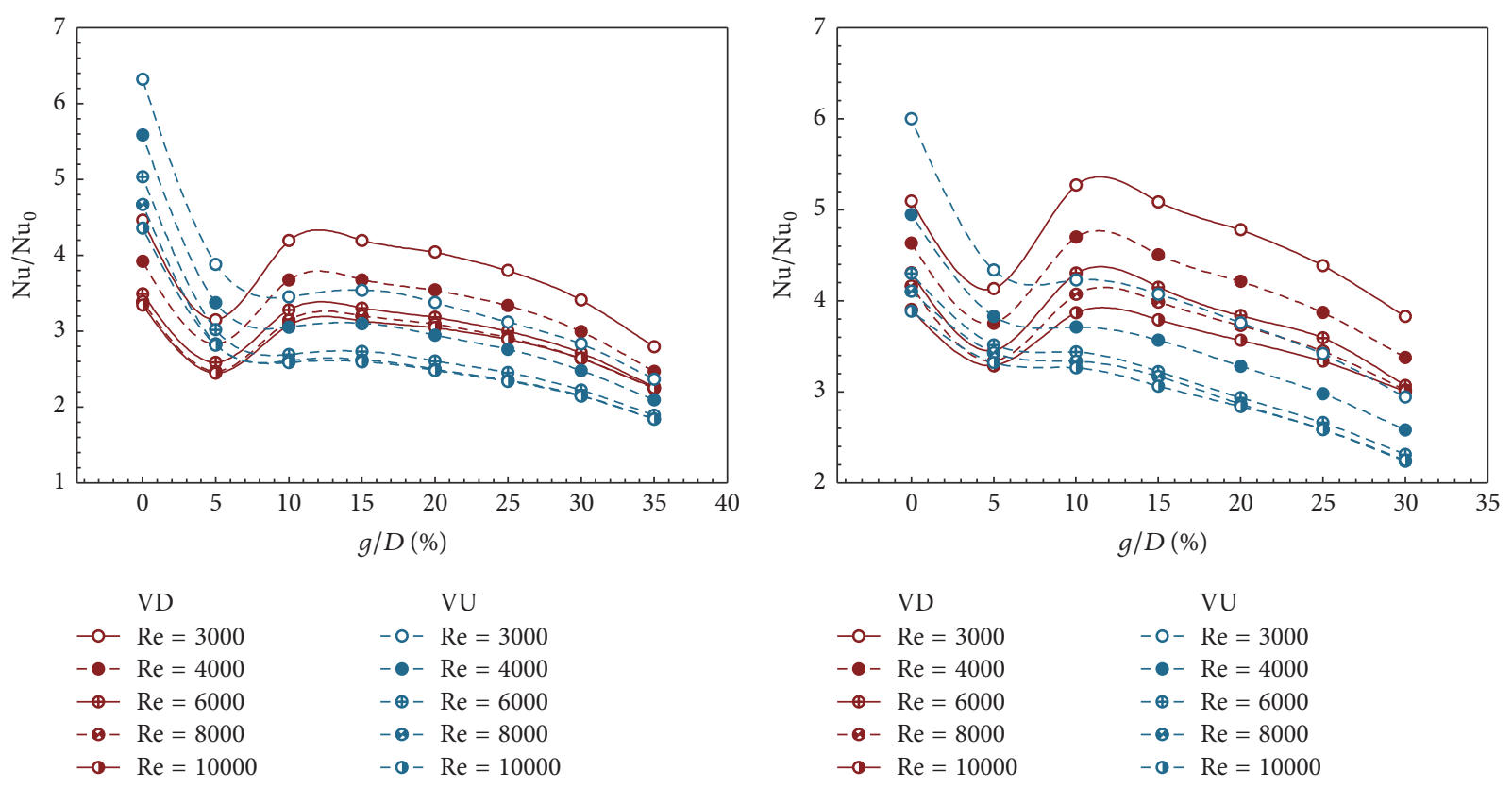

$$
\begin{gathered}
\mathrm{VU} \\
- \text { - } \mathrm{Re}=3000 \\
-\bullet-\mathrm{Re}=4000 \\
-\oplus-\mathrm{Re}=6000 \\
-\bullet-\mathrm{Re}=8000 \\
-\bullet-\mathrm{Re}=10000
\end{gathered}
$$

(a)

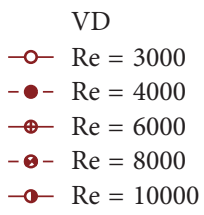

$\multimap \mathrm{Re}=10000$

$$
\begin{gathered}
\mathrm{VU} \\
-\circ-\mathrm{Re}=3000 \\
-\bullet-\mathrm{Re}=4000 \\
-\oplus-\mathrm{Re}=6000 \\
-\bullet-\mathrm{Re}=8000 \\
-\bullet-\mathrm{Re}=10000
\end{gathered}
$$

(b)

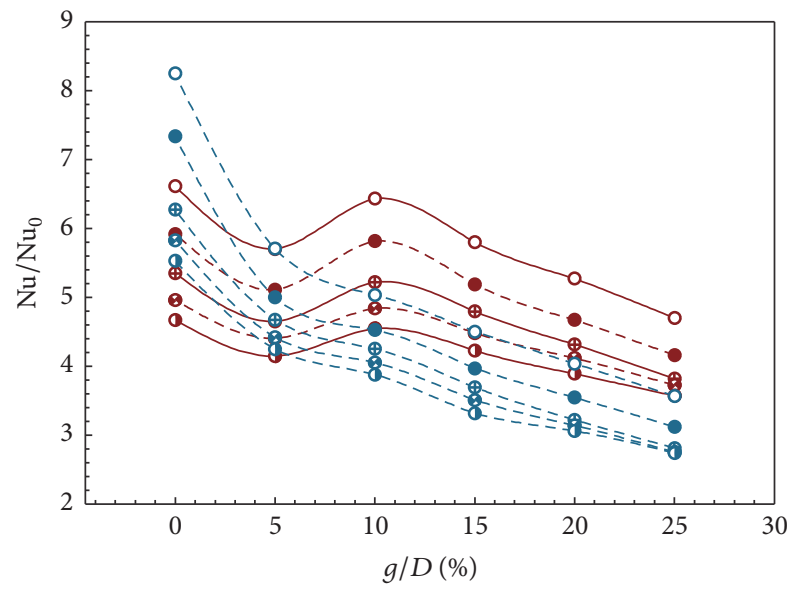

$\begin{array}{cc}\mathrm{VD} & \mathrm{VU} \\ -\mathrm{-} \mathrm{Re}=3000 & - \text { - } \mathrm{Re}=3000 \\ -\bullet \mathrm{Re}=4000 & -\bullet \mathrm{Re}=4000 \\ -\mathrm{Re}=6000 & -\oplus \mathrm{Re}=6000 \\ -\mathrm{-}-\mathrm{Re}=8000 & -\odot \mathrm{Re}=8000 \\ -\mathrm{-}-\mathrm{Re}=10000 & -\bullet-\mathrm{Re}=10000\end{array}$

(c)

FIGURE 27: $\mathrm{Nu} / \mathrm{Nu}_{0}$ versus $g / D$ for (a) $\mathrm{BR}=0.1$, (b) $\mathrm{BR}=0.15$, and (c) $\mathrm{BR}=0.2$.

$u_{i}$ : Velocity in $x_{i}$-direction, $\mathrm{m} \mathrm{s}^{-1}$

$\bar{u}$ : Mean velocity in channel, $\mathrm{m} \mathrm{s}^{-1}$.

\section{Greek Letters}

$\mu$ : Dynamic viscosity, $\mathrm{kg} \mathrm{s}^{-1} \mathrm{~m}^{-1}$

$\Gamma$ : Thermal diffusivity, $\left(=k / \rho c_{p}\right)$

$\alpha$ : Angle of attack, degree
TEF: Thermal enhancement factor

$$
\begin{array}{ll} 
& \left(=\left(\mathrm{Nu} / \mathrm{Nu}_{0}\right) /\left(f / f_{0}\right)^{1 / 3}\right) \\
\rho: \quad \text { Density, } \mathrm{kg} \mathrm{m}^{-3} .
\end{array}
$$

\section{Subscripts}

in: Inlet

0: Smooth tube

pp: Pumping power. 

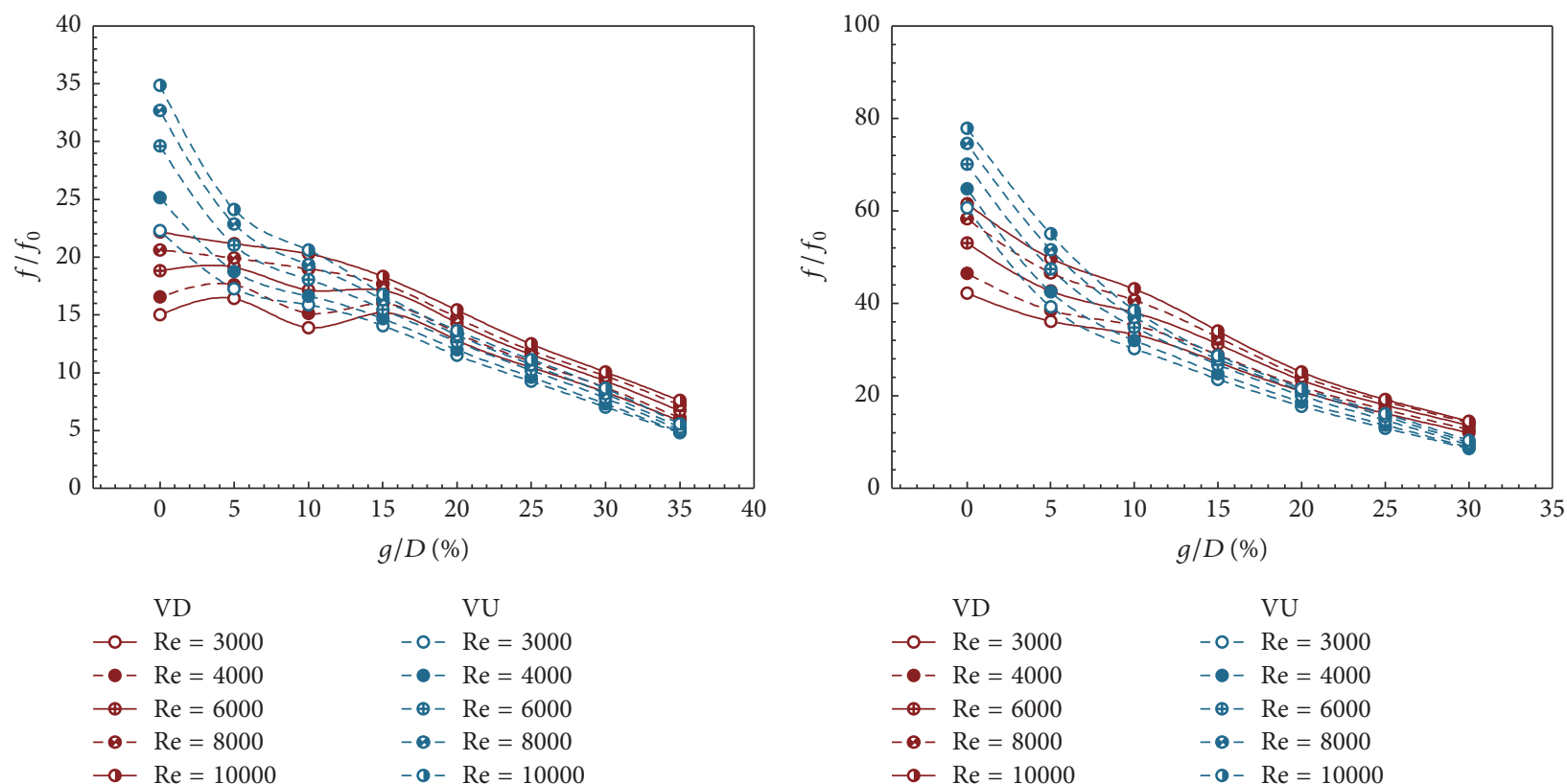

$$
\begin{aligned}
& \mathrm{VU} \\
&- \text { - } \mathrm{Re}=3000 \\
&-\bullet \mathrm{Re}=4000 \\
&-\oplus \mathrm{Re}=6000 \\
&-\bullet-\mathrm{Re}=8000 \\
&-\bullet-\mathrm{Re}=10000
\end{aligned}
$$

(a)

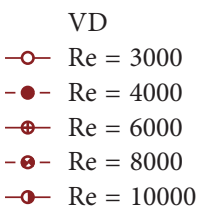

$-\mathrm{o}-\mathrm{Re}=10000$

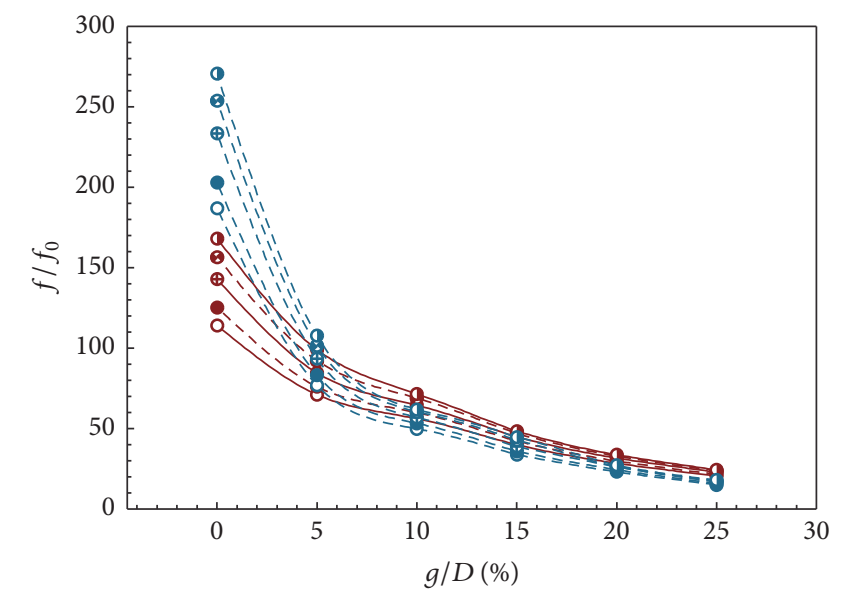

$\mathrm{VD}$

$$
\begin{aligned}
& \text {-O } \mathrm{Re}=3000 \\
& \text { - - } \mathrm{Re}=4000 \\
& \text { - }-\mathrm{Re}=6000 \\
& \text { - - } \mathrm{Re}=8000 \\
& \text {-๑ } \mathrm{Re}=10000
\end{aligned}
$$

$\mathrm{VU}$

$$
\begin{aligned}
& -\mathrm{-}-\mathrm{Re}=3000 \\
& -\bullet \mathrm{Re}=4000 \\
& -\oplus-\mathrm{Re}=6000 \\
& -\bullet-\operatorname{Re}=8000 \\
& -\bullet-\operatorname{Re}=10000
\end{aligned}
$$

(c)

\section{Conflicts of Interest}

The authors declare that there are no conflicts of interest regarding the publication of this article.

\section{Acknowledgments}

This research was funded by College of Industrial Technology, King Mongkut's University of Technology North Bangkok (Grant no. Res-CIT0208/2017). The authors would like to thank Associate Professor Dr. Pongjet Promvonge, KMITL, for suggestions.

\section{References}

[1] V. Kongkaitpaiboon, K. Nanan, and S. Eiamsa-ARD, "Experimental investigation of convective heat transfer and pressure loss in a round tube fitted with circular-ring turbulators," International Communications in Heat and Mass Transfer, vol. 37, pp. 568-574, 2010.

[2] K. Yakut and B. Sahin, "Flow-induced vibration analysis of conical-rings used of heat transfer enhancement in heat exchanger," Applied Energy, vol. 78, pp. 273-288, 2004.

[3] K. Yakut, B. Sahin, and S. Canbazoglu, "Performance and flowinduced vibration characteristics for conical-ring turbulators," Applied Energy, vol. 79, pp. 65-76, 2004. 
[4] A. Durmuş, "Heat transfer and exergy loss in cut out conical turbulators," Energy Conversion and Management, vol. 45, pp. 785-796, 2004.

[5] S. Eiamsa-ARD and P. Promvonge, "Experimental investigation of heat transfer and friction characteristics in a circular tube fitted with V-nozzle turbulators," International Communications in Heat and Mass Transfer, vol. 33, pp. 591-600, 2006.

[6] S. Eiamsa-ARD and P. Promvonge, "Effect of V-nozzle inserts and snail with free spacing entry on heat transfer in a heat exchanger," Journal of Energy Heat and Mass Transfer, vol. 28, pp. 225-239, 2006.

[7] P. Promvonge and S. Eiamsa-ARD, "Heat transfer augmentation in a circular tube using V-nozzle turbulator inserts and snail entry," Experimental Thermal and Fluid Science, vol. 32, pp. 332340, 2007.

[8] P. Promvonge and S. Eiamsa-ARD, "Heat transfer and turbulent flow friction in a circular tube fitted with conical-nozzle turbulators," International Communications in Heat and Mass Transfer, vol. 34, no. 1, pp. 72-82, 2007.

[9] P. Promvonge and S. Eiamsa-ard, "Heat transfer in a circular tube fitted with free-spacing snail entry and conical-nozzle turbulators," International Communications in Heat and Mass Transfer, vol. 34, no. 7, pp. 838-848, 2007.

[10] P. Promvonge and S. Eiamsa-ARD, "Heat transfer behaviors in a tube with combined conical-ring and twisted-tape insert," International Communications in Heat and Mass Transfer, vol. 34, no. 7, pp. 849-859, 2007.

[11] V. Kongkaitpaiboon, K. Nanan, and S. Eiamsa-ARD, "Experimental investigation of heat transfer and turbulent flow friction in a tube fitted with perforated conical-rings," International Communications in Heat and Mass Transfer, vol. 37, no. 5, pp. 560-567, 2010.

[12] V. Ozceyhan, S. Gunes, O. Buyukalaca, and N. Altuntop, "Heat transfer enhancement in a tube using circular cross sectional rings separated from wall," Applied Energy, vol. 85, no. 10, pp. 988-1001, 2008.

[13] S. O. Akansu, "Heat transfers and pressure drops for porousring turbulators in a circular pipe," Applied Energy, vol. 83, no. 3, pp. 280-298, 2006.

[14] R. Kiml, S. Mochizuki, A. Murata, and V. Stoica, "Effects of ribinduced secondary flow on heat transfer augmentation inside a circular tube," Journal of Enhanced Heat Transfer, vol. 10, no. 1, pp. 9-20, 2003.

[15] R. Kiml, A. Magda, S. Mochizuki, and A. Murata, "Rib-induced secondary flow effects on local circumferential heat transfer distribution inside a circular rib-roughened tube," International Journal of Heat and Mass Transfer, vol. 47, no. 6-7, pp. 1403-1412, 2004.

[16] C. Thianpong, K. Yongsiri, K. Nanan, and S. Eiamsa-ARD, "Thermal performance evaluation of heat exchangers fitted with twisted-ring turbulators," International Communications in Heat and Mass Transfer, vol. 39, no. 6, pp. 861-868, 2012.

[17] W. Jedsadaratanachai and A. Boonloi, "Effects of blockage ratio and pitch ratio on thermal performance in a square channel with $30^{\circ}$ double V-baffles," Case Studies in Thermal Engineering, vol. 4, pp. 118-128, 2014.

[18] S. Tamna, S. Skullong, C. Thianpong, and P. Promvonge, "Heat transfer behaviors in a solar air heater channel with multiple V-baffle vortex generators," Solar Energy, vol. 110, pp. 720-735, 2014.

[19] S. Singh, S. Chander, and J. S. Saini, “Thermo-hydraulic performance due to relative roughness pitch in $\mathrm{V}$-down rib with gap in solar air heater duct-comparison with similar rib roughness geometries," Renewable and Sustainable Energy Reviews, vol. 43, pp. 1159-1166, 2015.

[20] R. Karwa and G. Chitoshiya, "Performance study of solar air heater having v-down discrete ribs onabsorber plate," Energy, vol. 55, pp. 939-955, 2013.

[21] P. Promvonge, W. Changcharoen, S. Kwankaomeng, and C. Thianpong, "Numerical heat transfer study of turbulent squareduct flow through inline V-shaped discrete ribs," International Communications in Heat and Mass Transfer, vol. 38, no. 10, pp. 1392-1399, 2011.

[22] S. Singh, S. Chander, and J. S. Saini, "Investigations on thermohydraulic performance due to flow-attack-angle in V-down rib with gap in a rectangular duct of solar air heater," Applied Energy, vol. 97, pp. 907-912, 2012.

[23] V. S. Hans, R. P. Saini, and J. S. Saini, "Heat transfer and friction factor correlations for a solar air heater duct roughened artificially with multiple v-ribs," Solar Energy, vol. 84, no. 6, pp. 898-911, 2010.

[24] S. Singh, S. Chander, and J. S. Saini, "Heat transfer and friction factor correlations of solar air heater ducts artificially roughened with discrete V-down ribs," Energy, vol. 36, no. 8, pp. 5053-5064, 2011.

[25] V. SriHarsha, S. V. Prabhu, and R. P. Vedula, "Influence of rib height on the local heat transfer distribution and pressure drop in a square channel with $90^{\circ}$ continuous and $60^{\circ}$ V-broken ribs," Applied Thermal Engineering, vol. 29, no. 11-12, pp. 2444-2459, 2009.

[26] R. Karwa and K. Chauhan, "Performance evaluation of solar air heaters having $\mathrm{v}$-down discrete rib roughness on the absorber plate," Energy, vol. 35, no. 1, pp. 398-409, 2010.

[27] X.-Y. Tang and D.-S. Zhu, "Flow structure and heat transfer in a narrow rectangular channel with different discrete rib arrays," Chemical Engineering and Processing: Process Intensification, vol. 69, pp. 1-14, 2013.

[28] W. Peng, P.-X. Jiang, Y.-P. Wang, and B.-Y. Wei, "Experimental and numerical investigation of convection heat transfer in channels with different types of ribs," Applied Thermal Engineering, vol. 31, no. 14-15, pp. 2702-2708, 2011.

[29] P. Promthaisong, W. Jedsadaratanachai, and S. Eiamsa-Ard, “3D Numerical study on the flow topology and heat transfer characteristics of turbulent forced convection in spirally corrugated tube," Numerical Heat Transfer; Part A: Applications, vol. 69, no. 6, pp. 607-629, 2016.

[30] B. E. Launder and D. B. Spalding, "The numerical computation of turbulent flows," Computer Methods in Applied Mechanics and Engineering, vol. 3, no. 2, pp. 269-289, 1974.

[31] S. V. Patankar, "Numerical Heat Transfer and Fluid Flow, Hemisphere," Wash, USA, 1980.

[32] F. Incropera and P. D. Dewitt, Fundamentals of Heat and Mass Transfer, Wiley, NY, USA, 5th edition, 2002. 


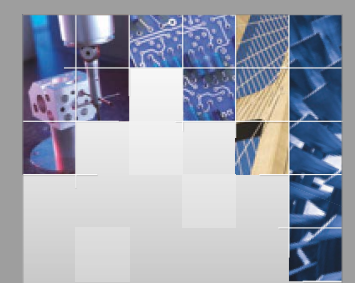

\section{Enfincering}
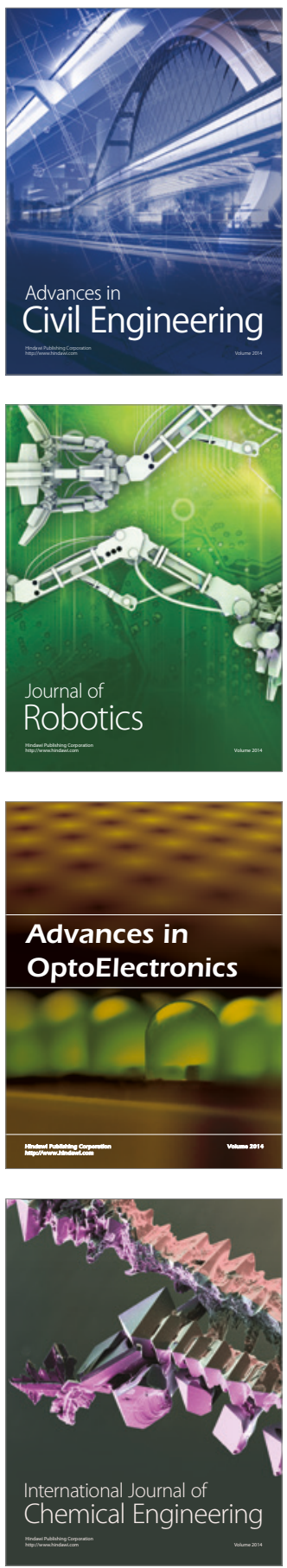

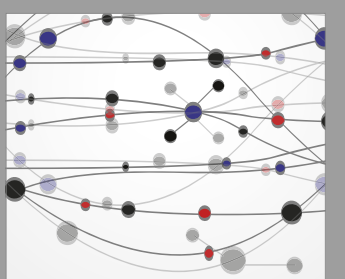

The Scientific World Journal

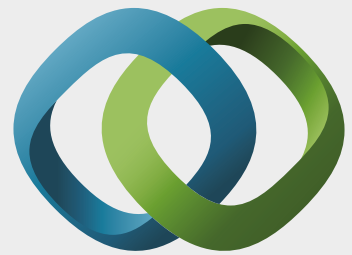

\section{Hindawi}

Submit your manuscripts at

https://www.hindawi.com
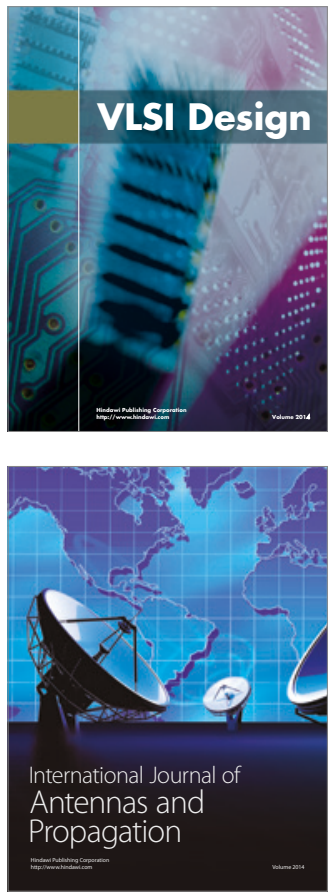

\section{Rotating}

Machinery
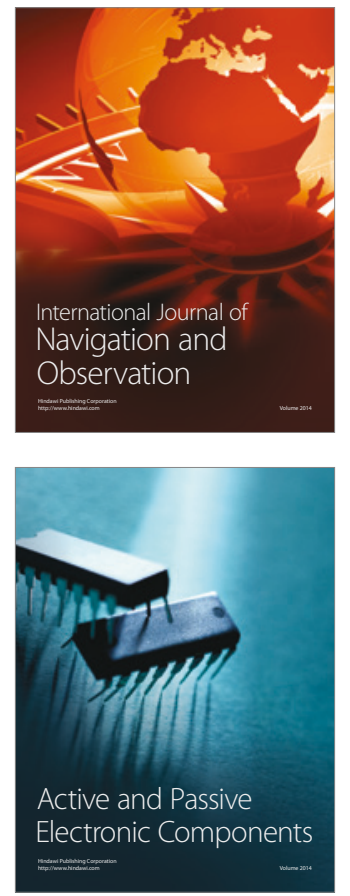
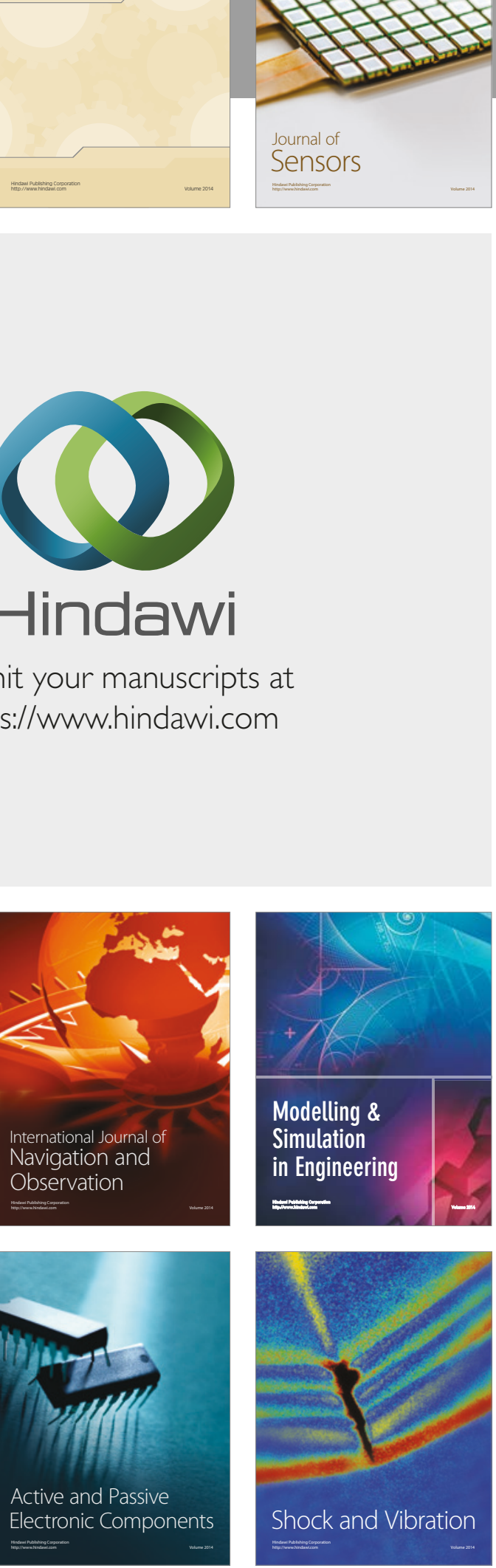
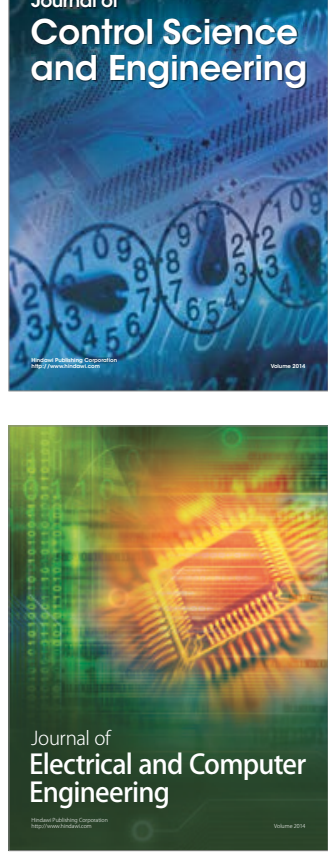

Distributed

Journal of

Control Science

and Engineering
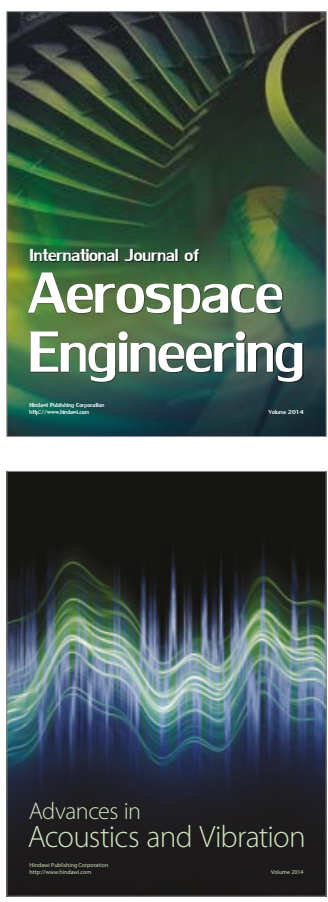

Sensor Networks 